\title{
Modelling aggregate formation and sedimentation of organic and mineral particles
}

\author{
Wolfgang Barkmann, Christian Schäfer-Neth ${ }^{1}$, Wolfgang Balzer * \\ University of Bremen, FB 2, Marine Chemistry, D-28334 Bremen, Germany
}

\section{A R T I C L E I N F O}

\section{Article history:}

Received 8 July 2009

Received in revised form 28 January 2010

Accepted 3 February 2010

Available online $\mathrm{xxxx}$

\section{Keywords:}

Aggregation

Dust

Modelling

Sedimentation

\begin{abstract}
A B S T R A C T
A one-dimensional model "ADAM" is presented that allows the prognostic computation of the interactions between mineral particles (dust) and biologically formed aggregates. The model couples a 7-compartment biogeochemical component $\left(\mathrm{NO}_{3}, \mathrm{NH}_{4}\right.$, phytoplankton aggregates, zooplankton, detritus, carbon, and chlorophyll) and a 4-compartment component for the tracing of mineral particles: single free particles in the water, particles aggregated with phytoplankton, incorporated in zooplankton, and attached to detritus. It resolves both annual and daily cycles of plankton and the fate of dust from eolian import into the ocean via biological activity, aggregation and disaggregation to sedimentation at the sea floor. The model results suggest that particle scavenging is essentially occurring in the mixed layer, where biological activity and shear aggregation regulate the formation of the aggregates. The aggregates interact intensively with the suspended pool of dust particles, and sink through the upper main thermocline with increasing speed. Particle break up and organic matter degradation are important mechanisms for particle cycling in the intermediate and deeper layers. The model predicts an $80 \%$ decrease of the annual carbon flux between $100 \mathrm{~m}$ and $3000 \mathrm{~m}$ depth. The vertical profile of Al-contents in suspended particulates and the annual average vertical flux of particulate organic matter are fairly well reproduced by the model, as well as the seasonal cycles of carbon and dust fluxes in the ocean interior.
\end{abstract}

(c) 2010 Elsevier B.V. All rights reserved.

\section{Introduction}

The removal of material from oceanic surface waters and its subsequent transport to the ocean interior is driven by the formation and sinking of particles. However, only larger particles with high settling rates significantly contribute to the vertical flux reaching the deep-sea (McCave, 1984). Collection of smaller particles into larger ones by aggregate formation has been invoked to explain the number of larger particles which are necessary to sustain the deep particulate flux. While the particle spectrum of biogenic particles includes larger primary particles (e.g., foraminifera), the lithogenic phases due to their mode of transportation to the surface ocean are generally smallsized and require some kinds of scavenging processes to explain their short residence time in the water column.

Since the early deep-sea deployments of time-series sediment traps (Deuser et al., 1981) a correlation of the fluxes of organic carbon and mostly abiogenic aluminum was observed in the Sargasso Sea (Deuser et al., 1983), in the Arabian Sea (Ramaswamy et al., 1991; Haake et al., 1993; Honjo et al., 1999) and in the tropical North and South Atlantic (Balzer, unpublished data). This may not be anticipated because lithogenic particles originate from eolian inputs controlled by

\footnotetext{
* Corresponding authors.

E-mail address: balzer@mch.uni-bremen.de (W. Balzer).

${ }^{1}$ Now at Alfred-Wegener-Institute, Computing Centre, D-27570 Bremerhaven, Germany.
}

random wind and/or rainfall or riverine sources, while fluxes of organic materials are related to the annual productivity cycle governed by nutrient supply, insolation and mixed layer dynamics. Obviously, these driving forces do not need to be correlated in time, and the coupling of biogenic and lithogenic particles must be attributed to processes in the water column, such as aggregation (Alldredge and Jackson, 1995), disaggregation, adsorption, and transfers associated with biological activities (e.g., formation of fecal pellets). Mineral particles-such as dust grains-are one of the primary sources of dissolved marine micro-nutrients like $\mathrm{Fe}, \mathrm{Mn}, \mathrm{Ni}$, or Co so that processes linking the sedimentation of organic and mineral material may have an influence on marine life.

Although it is largely accepted (e.g., Clegg and Whitfield, 1990; Murnane et al., 1990, 1994, 1996) that the joint fluxes of biogenic and non-biogenic materials are due to relatively large and fast-sinking particles, the relative importance of the mentioned processes linking lithogenic and biogenic matter during the formation of bigger particles from the smaller ones is still poorly understood. Below the surface mixed layer, the concentration of the slowly or non-sinking mineral grains in the water column (as part of the suspended particulate material, SPM) is affected by the sinking speed of the joint aggregates, their disaggregation/re-aggregation and by the remineralization rate of the organic material keeping the aggregate components together. Because during remineralization the mineral part of the joint aggregates can be released as a stable suspended particle while organics are converted to dissolved products, the distribution of 
particulate alumosilicates in the water column reflects the interplay of the different processes and may be used as an additional diagnostic tool for the analysis of joint vertical transport processes. To study the interactions between lithogenic particles and biogenic aggregates, we developed a one-dimensional biogeochemical model for both organic and stable mineral particles named "ADAM", after the variables it is aimed at: algae (phytoplankton aggregates), dust (mineral particles), animals (zooplankton), and trace metals (micro-nutrients). The model is suitable for implementation into three-dimensional biogeochemical circulation models.

Current biogeochemical models exist in a wide variety of configurations (Evans and Garçon, 1997). In the simplest case they consist of one type of nutrient, commonly nitrate, a phytoplankton and a zooplankton compartment, and a detritus pool to accomplish sinking of biogenic particles (Denman and Gargett, 1995; Doney et al., 1996). At the complex end of the scale, there are models with different phyto- and zooplankton types (e.g., Pondaven et al., 1998; Slagstad and Wassmann, 2001) assimilating nitrate as well as silicate, phosphorus, and ammonia (e.g., Tett, 1998; Skogen, 1999). Such a diversity can also be found in the representation of different particles sizes and their sinking modes. Extending the case of a single compartment for sinking detritus, some models distinguish between slowly and more rapidly sinking particle pools (e.g., Haupt et al., 1999; Dadou et al., 2001). There are a number of models that consider more than two classes of sinking particles and include particle-particle interactions (Jackson, 1990; Hill, 1996; Li and Zhang, 2003; Stemmann et al., 2004a,b). At comparably high computational costs, a complex model by Riebesell and Wolf-Gladrow (1992) tracks 1000 particle classes of increasing size on their way through the water column while including aggregation-disaggregation processes between these classes. To reduce computation time but retain detailed information on size-dependent particle properties, Kriest and Evans (1999, "KE99" hereafter) employed a continuous particle size spectrum characterized by two prognostic variables (aggregates and phytoplankton biomass). Gelbard et al. (1980) developed a hybrid formulation with only few particle classes, each defined individually by a continuous size spectrum. This approach originally applied to aerosol dynamics enables a more complex description of particle properties than that of KE99, while keeping computing times far below those of the Riebesell and Wolf-Gladrow (1992) model.

Based on data for different thorium isotopes, common models of trace metal scavenging with only two particle classes (smaller and larger than $50 \mu \mathrm{m}$ ) evaluate the rate constants for aggregation and disaggregation either by a direct comparison with observations (Clegg and Whitfield, 1990; Cochran et al., 1993) or by inverse methods using linear or non-linear least square algorithms (Murnane et al., 1990, 1996). Following the work of Burd and Jackson (1997), Burd et al. (2000) introduced a more sophisticated model of thorium scavenging by employing a sectional method using 52 size classes. This approach allowed for the modelling of aggregation and adsorption/desorption processes in more detail.

In our study, we present a dynamic model that accounts for the transport of mineral particles as an independent tracer, from their input at the sea surface until deposition at the ocean floor. This is achieved by modelling the interaction between and the joint sedimentation of biogenic and mineral particles, and we focus on the processes and parameters linking both. Therefore, we adopted a simple nitrogen-based biological model, and applied a single continuous particle size spectrum after KE99 and Kriest (2002), according to observed particle size distributions (McCave, 1984; Bader, 1970). The formulation of the KE99 particle dynamics allows the coupled phytoplankton/dust model to be easily incorporated into regional and global oceanic circulation models.

Based on annual cycles of insolation, mixed layer depth, up- and downwelling velocities and the nutrient field of the central Arabian Sea, our goal is to simulate a) the seasonal patterns of the deep-sea fluxes of organic carbon and aluminum (Fig. 1), b) the observed vertical profiles of particulate $\mathrm{Al}$ which were obtained from in-situ pump deployments in the Arabian Sea, and c) the annual average profile of organic carbon flux.

\section{The model}

ADAM comprises two conceptual parts. The first one is a nitrogenbased 1-dimensional model of nitrate, $\mathrm{NO}_{3}$, ammonia, $\mathrm{NH}_{4}$, phytoand zooplankton, PHY , ZOO, and detritus, DET (all variables given in units of [ $\left.\mathrm{mg} \mathrm{N} \mathrm{m}^{-3}\right]$ ). Following the approach of KE99, phytoplankton and detritus are represented as aggregates containing both living cells and detritus particles. Modelling of aggregation processes and aggregate sinking is based on a continuous size spectrum for the aggregates, characterized by the prognostic variables for total aggregate mass, PHY + DET , and total aggregate number concentration, NOS, [particles $/ \mathrm{m}^{3}$ ]. ADAM's second part computes the aggregation of dust grains with phytoplankton and detritus, the transfers of dust between the different biological compartments, and the vertical dust transport with sinking aggregates. Each model variable is a function of depth and time. ADAM extends over $5000 \mathrm{~m}$ depth using 300 levels, with thicknesses increasing linearly from $2 \mathrm{~m}$ at the top to about $31 \mathrm{~m}$ at the bottom. To resolve the daily cycle of light, the time step is set to $4 \mathrm{~h}$. For time stepping, the modified midpoint method (Press et al., 1986) is employed.

The model is driven by daily and annual cycles of insolation, mixed layer depth, and up- and downwelling velocities that are taken from observations, climatological data and 1-D mixed layer model results, and by a dust deposition rate according to literature.

\subsection{Model structure}

The model combines three different components. These are

a) a common NPZD-model that calculates the time and depth evolution of nitrogen, phytoplankton, zooplankton and detritus,

b) the aggregation model of KE99, including a disaggregation term, and c) a model of aggregation and joint sedimentation of lithogenic (dust) and biogenic material (phytoplankton, detritus).

The algorithms describing the biological model and the phytoplankton/detritus aggregation mechanisms can be found in the Appendices A and B. The equations governing aggregation between organic material and mineral particles are presented in the section below.

\subsection{The dust model}

To allow the model for dust-phytoplankton aggregation, we introduced four additional prognostic variables:

1. the concentration of free dust particles, (DUF), 2. and 3. the concentrations of dust bound in aggregates, that is, attached to phytoplankton (DUP) and detritus, (DUD), and 4. dust incorporated in zooplankton, (DUZ).

All variables are expressed as [particles $\left./ \mathrm{m}^{3}\right]$. Dust transfers between the biological compartments are assumed to co-vary with the respective transports of nitrogen. Thus, with the rates of eolian ocean surface dust input (eoli $(z=0)$ ) and dust-phytoplankton aggregation $(\chi)$, the equations for the dust compartments read:

$\frac{\partial \mathrm{DUF}}{\partial t}=+\mathrm{Q}_{\mathrm{PHY}} \mathrm{DUP}+\mathrm{Q}_{\mathrm{DET}} \mathrm{DUD}+$ eoli $-\chi+\mathrm{AD}$,

$\frac{\partial \mathrm{DUP}}{\partial t}=-\left(\mathrm{Q}_{\mathrm{PHY}}+\mu_{\mathrm{PHY}}+\gamma \frac{\mathrm{ZOO}}{\mathrm{PHY}}\right) \mathrm{DUP}+\frac{\mathrm{PHY}}{\mathrm{PHY}+\mathrm{DET}} \chi+\mathrm{AD}+S_{\mathrm{DUP}}$, 


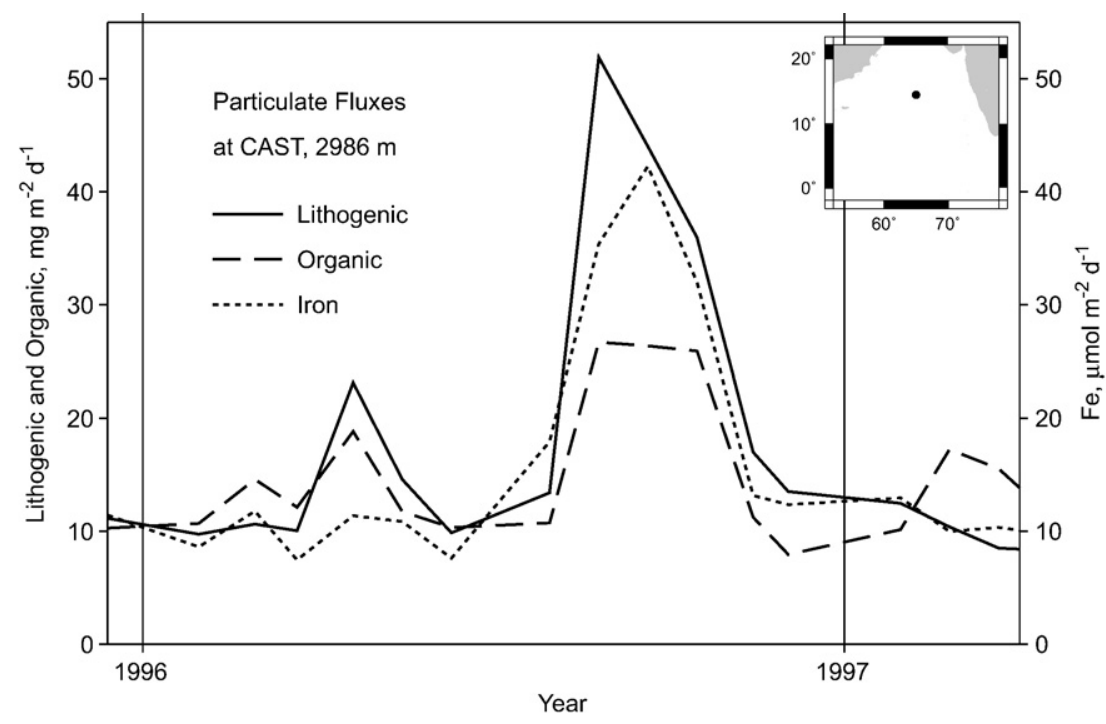

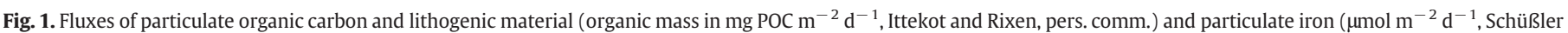
and Balzer, unpublished data) from sediment trap data at $2986 \mathrm{~m}$ depth, station CAST, years 1996 to 1997.

$$
\begin{aligned}
\frac{\partial \mathrm{DUD}}{\partial t}= & +\left(\mu_{\mathrm{PHY}}+(1-\sigma) \gamma \frac{\mathrm{ZOO}}{\mathrm{PHY}}\right) \mathrm{DUP}+\left(\mu_{\mathrm{ZOO}}+\phi \mathrm{ZOO}\right) \mathrm{DUZ} \\
& -\varrho_{\mathrm{DET}} \mathrm{DUD}+\frac{\mathrm{DET}}{\mathrm{PHY}+\mathrm{DET}} \chi+\mathrm{AD}+S_{\mathrm{DUD}},
\end{aligned}
$$

$\frac{\partial \mathrm{DUZ}}{\partial t}=+\sigma \gamma \frac{\mathrm{ZOO}}{\mathrm{PHY}} \mathrm{DUP}-\left(\mu_{\mathrm{ZOO}}+\phi \mathrm{ZOO}\right) \mathrm{DUZ}+\mathrm{AD}$.

with the phytoplankton and zooplankton mortalities $\mu_{\mathrm{PHY}}$ and $\mu_{\mathrm{ZOO}}$. $\varrho_{\mathrm{PHY}}$ and $\varrho_{\mathrm{DET}}$ represent the remineralization rates of phytoplankton and detritus, $\sigma$ and $\gamma$ refer to zooplankton assimilation and grazing (see Appendix A for further details). In addition to advection and diffusion $\mathrm{AD}$, these equations contain $S_{\mathrm{DUP}}$ and $S_{\mathrm{DUD}}$, the rates of change due to aggregate sinking.

$S_{\text {DUP }}=\frac{\partial\left(w_{\text {dust }} \text { DUP }\right)}{\partial z} ; S_{\text {DUD }}=\frac{\partial\left(w_{\text {dust }} \text { DUD }\right)}{\partial z} ;$

The equation for the dust mass sinking velocity, $w_{\text {dust }}$, is similar to that of the biomass sinking velocity $w_{\text {bio }}$ derived in Appendix B, but we changed the integral range from $m$ to $l$, with $\mathrm{l}>\mathrm{m}$ (see Section 3.3.2 for a discussion of the relationship between particle capture efficiency and integral range).

The simplifying assumption that dust co-varies with the different biological compartments may not generally be true (Fisher and Hook, 2002; Twining and Fisher, 2004), especially for zooplankton that might preferentially incorporate the biological parts of the aggregates but exude the mineral constituents. According to our results (see below) the zooplankton dust concentrations reach only $5 \%$ of the concentrations in phytoplankton, and we regard this issue to be of minor importance.

\subsubsection{The phytoplankton/detritus-dust aggregation term, $\chi$}

Rewriting the aggregation equations of Jackson (1990) for the interaction of two particle classes, one having a continuous size distribution, here phytoplankton (NOS), the other having a fixed diameter, free dust (DUF), gives for $\chi$, the number of collisions with subsequent sticking per volume and time,

$\chi=\operatorname{stick}_{d} \mathrm{DUF} \int_{l}^{\infty}\left(\beta_{\text {shear }}+\beta_{\text {sett }}\right) P(\Theta) d \Theta$, stick $_{d}$ is the probability of dust and aggregates sticking to each other after collision. The aggregation kernels of turbulent shear and differential settling are

$\beta_{\text {shear }}=\frac{\text { shear }}{6}\left(\Theta+m_{d}\right)^{3}$

$\beta_{\text {sett }}=\frac{\pi}{4} \Theta^{2}\left(w_{\Theta}-w_{d}\right)$,

with the dust particle diameter, $m_{d}$, and the aggregate diameter $\Theta$. The sinking velocities of dust and aggregates are denoted $w_{d}$ and $w_{\Theta}$, respectively, the latter defined empirically (Smayda, 1970; Alldredge and Gotschalk, 1988) by two constants as $w_{\Theta}=B \Theta^{\eta}$. Combining this yields

$$
\begin{aligned}
\chi= & \text { stick }_{d} \text { DUF } A \\
& \times\left[\frac{\text { shear }}{6} \int_{l}^{\infty}\left(\Theta+m_{d}\right)^{3} \Theta^{-\varepsilon} d \Theta+\frac{\pi}{4} \int_{l}^{\infty}\left(B \Theta^{2+\eta} \Theta^{-\varepsilon}-w_{d} \Theta^{2-\varepsilon}\right) d \Theta\right] .
\end{aligned}
$$

Analogous to the phytoplankton aggregation model of KE99 (see Appendix B), we split the integration range into two subranges, $l \leq \Theta \leq L$ and $L<\Theta \leq \infty$. For the latter subrange, the aggregation kernels are kept constant by substituting $L$ for $\Theta$ :

$$
\begin{aligned}
\chi= & \operatorname{stick}_{d} \text { DUF } A \\
& \times\left[\frac{\text { shear }}{6}\left(\int_{l}^{L}\left(\Theta+m_{d}\right)^{3} \Theta^{-\varepsilon} d \Theta+\left(L+m_{d}\right)^{3} \int_{L}^{\infty} \Theta^{-\varepsilon} d \Theta\right)\right. \\
& \left.+\frac{\pi}{4}\left(\int_{l}^{L} B \Theta^{2}+\eta^{-\varepsilon} d \Theta+w_{L} \int_{L}^{\infty} \Theta^{2-\varepsilon} d \Theta-w_{d} \int_{l}^{L} \Theta^{2-\varepsilon} d \Theta\right)\right],
\end{aligned}
$$

with $w_{L}=B L^{\eta}$ and $A=\operatorname{NOS}(\varepsilon-1) l^{\varepsilon-1}$, NOS = number of aggregates (see Appendix B for definition). After some algebra we obtain

$$
\begin{aligned}
\chi= & \text { stick }_{d} \text { DUF NOS }\left[\frac { \text { shear } } { 6 } \left(m_{d}^{3}\left(1-F_{L}\right)+3 m_{d}^{2} \frac{1-\varepsilon}{2-\varepsilon}\left(l-F_{L} L\right)\right.\right. \\
& \left.+3 m_{d} \frac{1-\varepsilon}{3-\varepsilon}\left(l^{2}-F_{L} L^{2}\right)+\frac{1-\varepsilon}{4-\varepsilon}\left(l^{3}-F_{L} L^{3}\right)+F_{L}\left(m_{d}+L\right)^{3}\right) \\
& \left.+\frac{\pi}{4}\left(w_{L} F_{L} L^{2}\left(\frac{1-\varepsilon}{3-\varepsilon}-\frac{1-\varepsilon}{3+\eta-\varepsilon}\right)+w_{l} l^{2} \frac{1-\varepsilon}{3+\eta-\varepsilon}+w_{d} \frac{l^{3-\varepsilon}}{3-\varepsilon}\right)\right],
\end{aligned}
$$

with the abbreviation $F_{L}=(L / l)^{1-\varepsilon}$. 


\section{Results}

To run the model we chose the following forcing data sets (Fig. 2):

Mixed layer depth and turbulent mixing coefficients were derived from the results of a mixed layer model (Gaspar et al., 1990) forced by surface momentum and heat fluxes at $15 \mathrm{~N}, 65 \mathrm{E}$. The forcing data as well as insolation were taken from observations made in the Arabian Sea in 1995 (Weller et al., 1998; S. Josey, pers. comm.). Up- and downwelling velocities were computed from depth variations of the 24C isotherm as given by Levitus and Boyer (1994). The vertical velocities decrease from the base of the mixed layer exponentially with depth. We assumed a horizontally homogenous tracer distribution to calculate the corresponding lateral fluxes, except for nitrogen. Here we used the Levitus and Boyer (1994) annual nitrogen profile. We set the dust input to a constant of $4.3 \mathrm{~g} \mathrm{~m}^{-2} \mathrm{a}^{-1}$. This value is based on sediment trap data recorded for the central Arabian Sea by Haake et al. (1993). Honjo et al. (1999) found a slightly higher value of $5.9 \mathrm{~g} \mathrm{~m}^{-2} \mathrm{a}^{-1}$ in 1995 at $15.5 \mathrm{~N}, 61.5 \mathrm{E}$. Keeping in mind that the interannual variability of physical and biological properties in the Arabian Sea is quite high (Kumar et al., 2001), these data sets provide a fairly consistent setting for studying processes in the "normal", that is, non El-Niño Arabian Sea (Kinkade et al., 2001) around 1995. We defined a set of parameter values listed in Table 1, which was used for the standard model integrations.

All results shown here were taken from year eighty of the model run. A twenty to forty year spin-up time was necessary to force the annual cycles of the biological and dust components into a quasi steady state (changes of the deep-sea dust profiles less than $0.1 \%$ per year). The initial dust profile was set to $4 \cdot 10^{-4} \mathrm{mg} \mathrm{m}^{-3}$, but a control run initialised with $7 \mathrm{mg}$ dust $\mathrm{m}^{-3}$ revealed that the model results were independent of the initial conditions.

\subsection{Phytoplankton and detritus, particle size distribution and sinking}

During the SW and NE monsoons, nutrients are entrained into the photic zone as a result of mixed layer deepening. In conjunction with high insolation, this leads to two phytoplankton blooms extending over the entire mixed layer, peaking around days 30 and 220 (Fig. 3, left panel). Modelled primary production reaches values between 530 and $860 \mathrm{mg} \mathrm{C} \mathrm{m}{ }^{-2} \mathrm{~d}^{-1}$ during these times of the year, which is about half of the 1995 rates of $1000-1500 \mathrm{mg} \mathrm{C} \mathrm{m}^{-2} \mathrm{~d}^{-1}$ reported by Barber et al. (2001) for the central Arabian Sea. The vertically integrated chlorophyll contents modelled alongside with phytoplankton biomass lie in the lower range of 1995 measurements (Kinkade et al., 2001; $15-45 \mathrm{mg} \mathrm{m}^{-2}$ ) from $15.5 \mathrm{~N}, 61.5 \mathrm{E}$. We regard this as an acceptable result, considering the high lateral variability of stocks and production in the eastern and central Arabian Sea and the limitations of a 1-D model. During intermonsoons, the supply of nutrients to the mixed layer ceases and the phytoplankton concentrations are reduced (around days 120 and 280). At the base of the mixed layer, small scale turbulent mixing from below still provides sufficient nutrients to support deep blooms that are almost as intense as the shallower ones. This is evident from the total number concentrations of aggregates in spring, too (Fig. 3, right). Here, the deep (60-80 m) concentrations $\left(>10^{10} \mathrm{~m}^{-3}\right)$ can exceed the surface ones $\left(<10^{10} \mathrm{~m}^{-3}\right)$, because shear aggregation in the mixed layer is higher than in the seasonal thermocline, where the deep chlorophyll maximum is located, leaving more but smaller aggregates in the deep bloom.

During the production periods of the SW and NE monsoons, shear aggregation and differential settling form aggregates of increasing size and sinking speed in the mixed layer, thus transferring biomass from the almost non-sinking pool of single plankton cells to the rapidly sinking aggregates (McCave, 1984; Clegg and Whitfield, 1990; Murnane et al., 1996). This triggers two main sedimentation events (Fig. 4) that export biogenic material to the deeper ocean. The slope of the particle size distribution $\varepsilon$ changes accordingly (Fig. 5). The

\section{Table 1}

Choice of model parameters used in this study. Parameters were set according to the ranges given by Pätsch et al. (2002), Evans and Garçon (1997), Kriest (2002), and KE99. Asterisks $\left({ }^{*}\right)$ denote parameters changed for the experiments discussed in the section on ADAM's sensitivity.

\begin{tabular}{|c|c|c|c|}
\hline Parameter & Symbol & Value & Unit \\
\hline \multicolumn{4}{|l|}{ Physics } \\
\hline Turbulent mixing below mixed layer & & 0.3 & $\mathrm{~cm}^{2} \mathrm{~s}^{-1}$ \\
\hline Turbulent mixing in mixed layer & & Up to 515 & $\mathrm{~cm}^{2} \mathrm{~s}^{-1}$ \\
\hline \multicolumn{4}{|l|}{ Phytoplankton } \\
\hline Half saturation of $\mathrm{NO}_{3}$ uptake & & 7 & $\mathrm{mg} \mathrm{N} \mathrm{m}{ }^{-3}$ \\
\hline Half saturation of $\mathrm{NH}_{4}$ uptake & & 1 & $\mathrm{mg} \mathrm{N} \mathrm{m} \mathrm{m}^{-3}$ \\
\hline $\begin{array}{l}\text { Maximum light- and N-saturated } \\
\text { growth rate }\end{array}$ & & 2.25 & $d^{-1}$ \\
\hline Initial slope of PI-curve & $\alpha$ & 1.165 & $10^{5}\left(\mathrm{Wm}^{-2}\right)^{-1} \mathrm{~s}^{-1}$ \\
\hline Maximum chl:carbon ratio & $\theta_{m}$ & 0.04 & \\
\hline * Remineralization rate & $\varrho_{\mathrm{PHY}}$ & 0.05 & $d^{-1}$ \\
\hline Mortality & $\mu_{\mathrm{PHY}}$ & 0.05 & $d^{-1}$ \\
\hline \multicolumn{4}{|l|}{ Detritus } \\
\hline${ }^{*}$ Remineralization rate & $\varrho_{\mathrm{DET}}$ & 0.05 & $d^{-1}$ \\
\hline \multicolumn{4}{|l|}{ Zooplankton } \\
\hline Mortality & $\mu_{\text {Zoo }}$ & 0.04 & $\mathrm{~d}^{-1}$ \\
\hline Quadratic loss parameter & $\phi$ & 0.04 & $\mathrm{~d}^{-1} / \mathrm{mg} \mathrm{N} \mathrm{m}^{-3}$ \\
\hline Assimilation efficiency & $\sigma$ & 0.75 & \\
\hline Phytoplankton threshold for grazing & & 1 & $\mathrm{mg} \mathrm{N} \mathrm{m}^{-3}$ \\
\hline \multicolumn{4}{|l|}{ Dust } \\
\hline Particle diameter & $m_{d}$ & 0.0001 & $\mathrm{~cm}$ \\
\hline *Dust-aggregates stickiness & stick $_{d}$ & 0.2 & \\
\hline Settling speed & $w_{d}$ & 0 & $\mathrm{md}^{-1}$ \\
\hline \multicolumn{4}{|l|}{$\begin{array}{l}\text { Lower aggregate size for differential } \\
\text { settling, }\end{array}$} \\
\hline shear aggregation and sinking & 1 & 0.00045 & $\mathrm{~cm}$ \\
\hline $\begin{array}{l}\text { Upper aggregate size for differential } \\
\text { settling and shear aggregation }\end{array}$ & $\mathrm{L}$ & 0.015 & $\mathrm{~cm}$ \\
\hline \multicolumn{4}{|l|}{ Aggregation } \\
\hline Mixed layer shear rate & shear & 1 & $s^{-1}$ \\
\hline Sub-mixed layer shear rate & shear & 0.01 & $s^{-1}$ \\
\hline Cell diameter & $m$ & 0.0001 & $\mathrm{~cm}$ \\
\hline $\begin{array}{l}\text { *Upper aggregate size for } \\
\text { computation of sinking }\end{array}$ & $M$ & 1 & $\mathrm{~cm}$ \\
\hline *Disaggregation time constant & $\kappa_{0}$ & 0.060 & $d^{-1}$ \\
\hline Disaggregation e-folding depth & $\lambda$ & 500 & $\mathrm{~m}$ \\
\hline $\begin{array}{l}\mathrm{N} \text { content exponent, } \\
\text { aggregate fractal dimension }\end{array}$ & $\zeta$ & 2 & \\
\hline$N$ content coefficient & C & 14,000 & $\mathrm{ng} \mathrm{N} \mathrm{cm}^{-\zeta}$ \\
\hline Sinking exponent & $\eta$ & 1 & \\
\hline $\begin{array}{l}\text { Sinking coefficient } \\
\rightarrow \text { cell and maximum } \\
\text { sinking velocities = } 1 \text { and } \\
500 \mathrm{~m} \mathrm{~d}^{-1}\end{array}$ & $B$ & 0.5787 & $\mathrm{~cm}^{1-\eta} \mathrm{s}^{-1}$ \\
\hline *Stickiness & stick & 1 & \\
\hline Separation probability & $\beta$ & 0.7 & \\
\hline \multicolumn{4}{|l|}{ Nutrients } \\
\hline $\begin{array}{l}\text { Maximum rate of } \mathrm{NH}_{4} \\
\text { to } \mathrm{NO}_{3} \text { regeneration }\end{array}$ & & 0.04 & $d^{-1}$ \\
\hline $\begin{array}{l}\text { Half saturation of } \mathrm{NH}_{4} \\
\text { to } \mathrm{NO}_{3} \text { regeneration }\end{array}$ & & 1.4 & $\mathrm{mg} \mathrm{N} \mathrm{m}{ }^{-3}$ \\
\hline
\end{tabular}

highest $\varepsilon$ values can be found during the spring intermonsoon period in the upper layers. $\varepsilon$ decreases with depth, i.e., the sinking velocity increases and shows a seasonal cycle with the highest sinking speed (Fig. 6) during the SW-monsoon. A similar increase of the sinking speed with depth was calculated by Berelson (2002) from observations. The modelled annual average deep-sea organic carbon flux of $16.8 \mathrm{mg} \mathrm{C} \mathrm{m}^{-2} \mathrm{~d}^{-1}$ compares fairly well with the observations of Lee et al. (1998) (11.1 $\mathrm{mg} \mathrm{C} \mathrm{m}^{-2} \mathrm{~d}^{-1}$ ) at $15.5 \mathrm{~N}, 61.5 \mathrm{E}$, except that in the depth range between 500 and $1000 \mathrm{~m}$, the model slightly overestimates the vertical annual carbon flux (see below). 


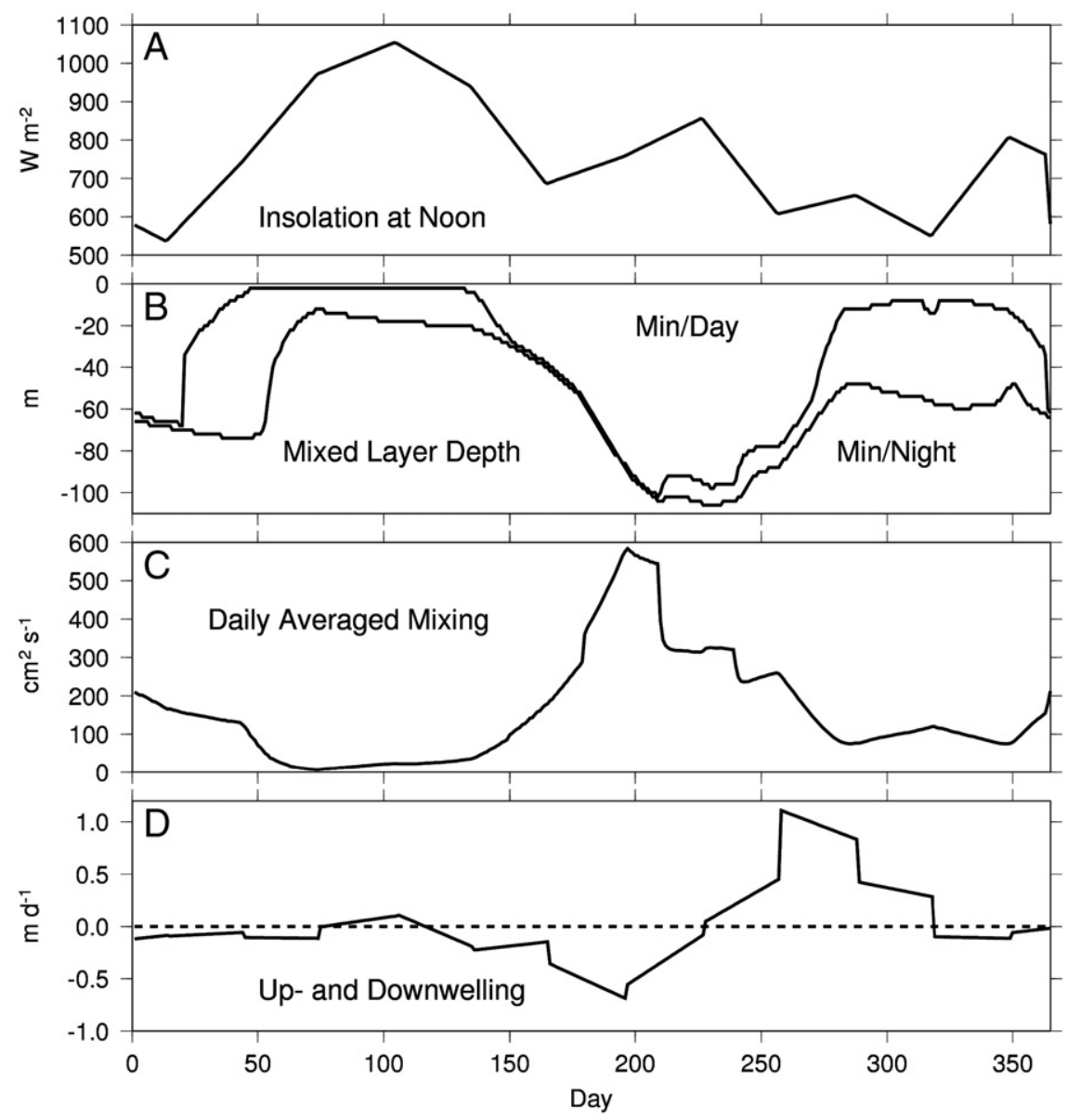

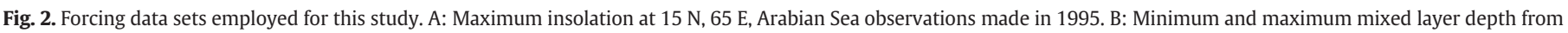

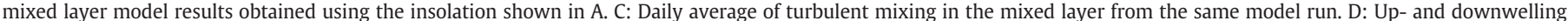

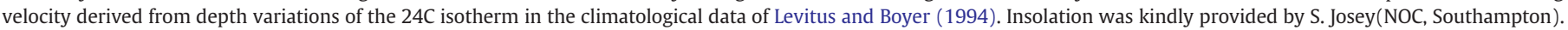

\subsection{Dust}

When biological activity is low, the majority of the dust particles in the photic zone appear as free dust particles due to its low sedimentation rate (Fig. 7, left and top right). With the onset of the bloom, the dust grains are incorporated into the aggregates (Fig. 7, top right). Compared to the concentrations of free and aggregated dust, the concentrations of dust within zooplankton stay relatively low (Fig. 7, bottom right). With the sinking aggregates, the dust particles are removed to greater depth (Fig. 8). This is consistent with observations where fine-grained particles stay in the upper ocean until biologically induced sedimentation events occur (Ramaswamy et al., 1991; Passow et al., 2001; Schüßler et al., 2005). Experiments using different time-varying dust inputs confirmed this result: Without biological activity, dust mainly accumulates in the
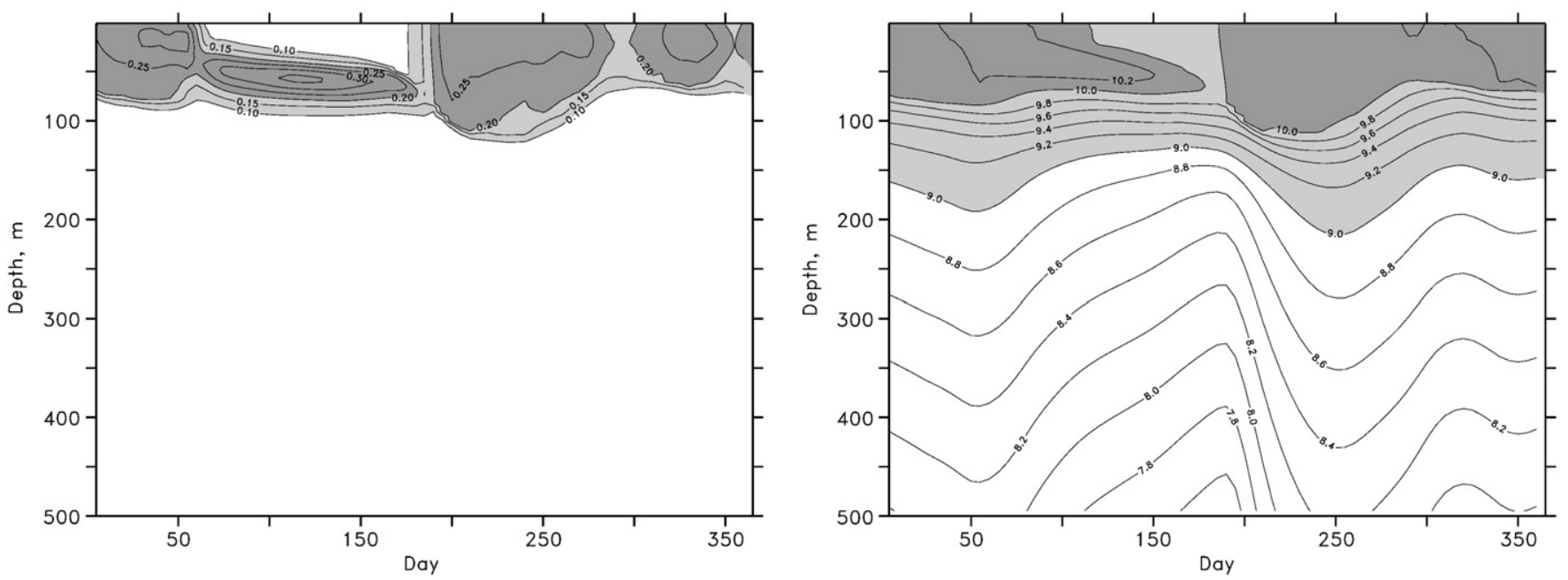

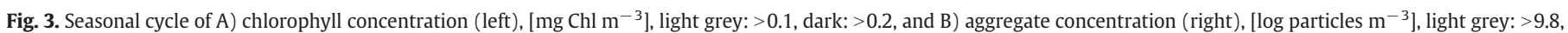
dark: $>10$. 


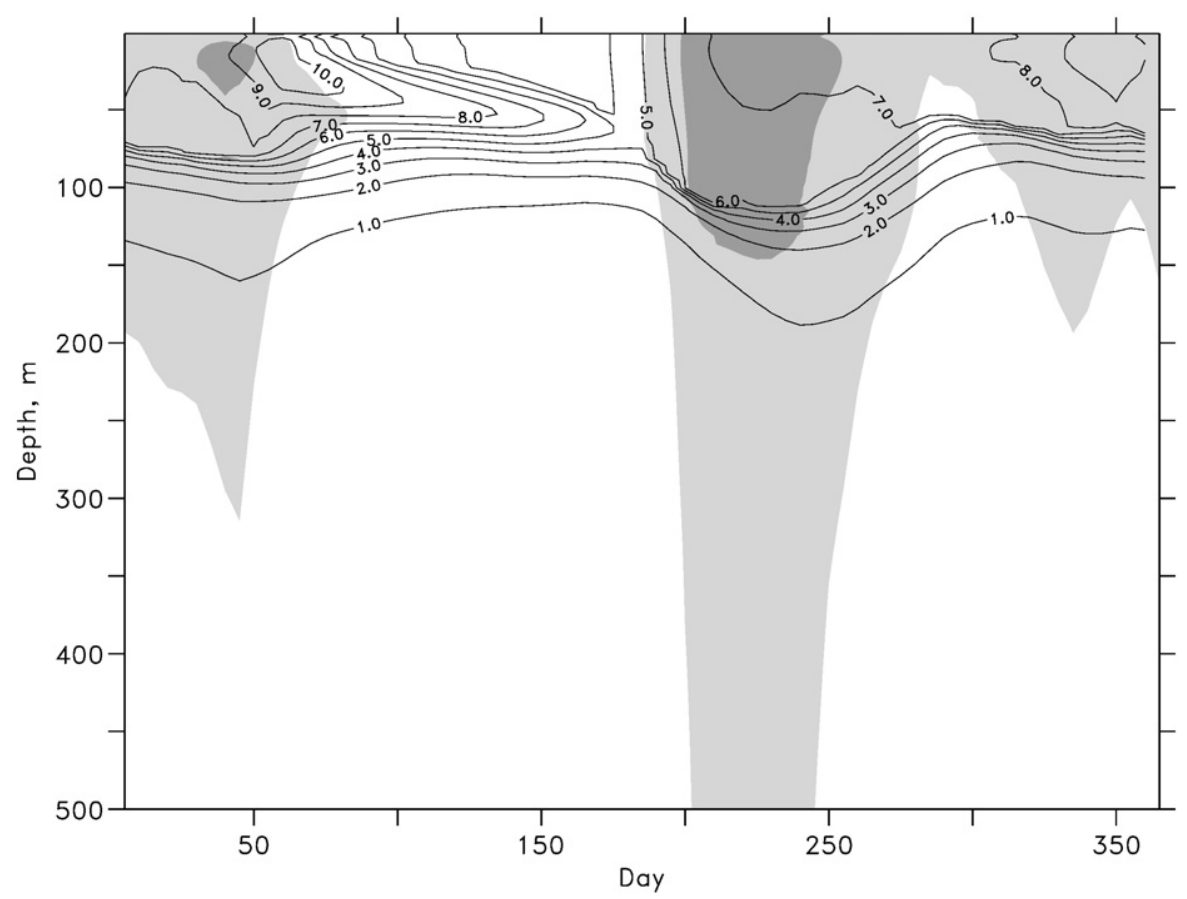

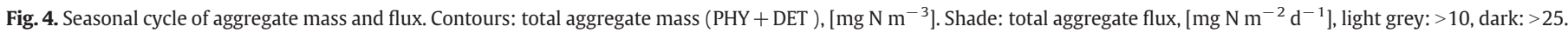

upper ocean, "waiting" for a phytoplankton bloom to take it down. During the sinking of the aggregates, aggregate decay and remineralization of the organic carrier release the mineral particles to the water column, leading to the increasing concentrations of free particles below the mixed layer as can be seen in Fig. 7 (left). The modelled dust concentration of day 100 (mid of April, spring intermonsoon) in comparison with SPM profiles from in-situ-pump stations (Al-concentration converted to dust concentration, conversion factor $=0.08$ ) are shown in Fig. 9. The dust profiles (free dust and total dust) closely follow the measured ones, from high concentrations near the surface over an intermediate minimum at around $100-200 \mathrm{~m}$ to higher and almost constant values below $600 \mathrm{~m}$.

\subsection{Sensitivity of the model}

The simulation of the annual dust flux in the deeper ocean appears to be realistic, and the source of the free dust grains (remineralization of organic material) is balanced by the aggregation between dust and

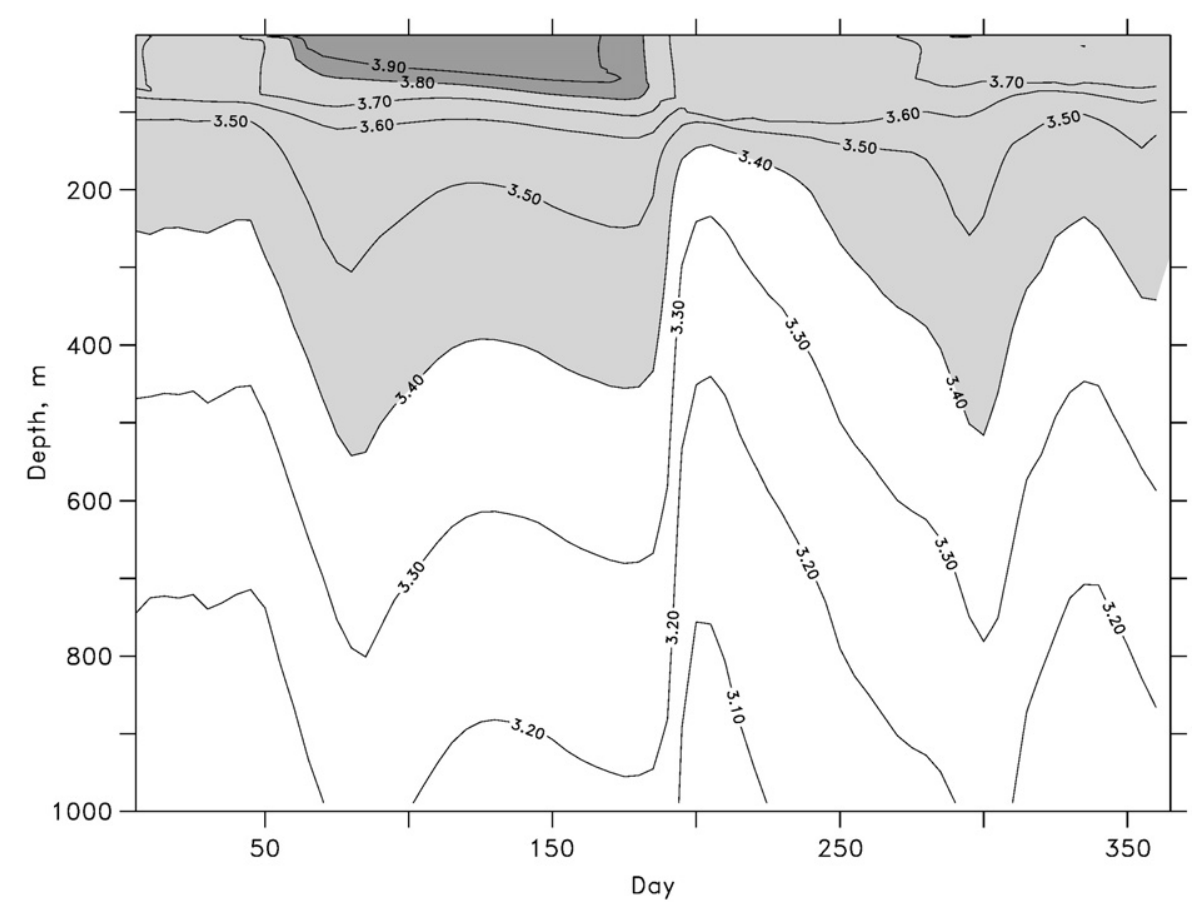

Fig. 5. Seasonal cycle of particle size distribution $\varepsilon$. 


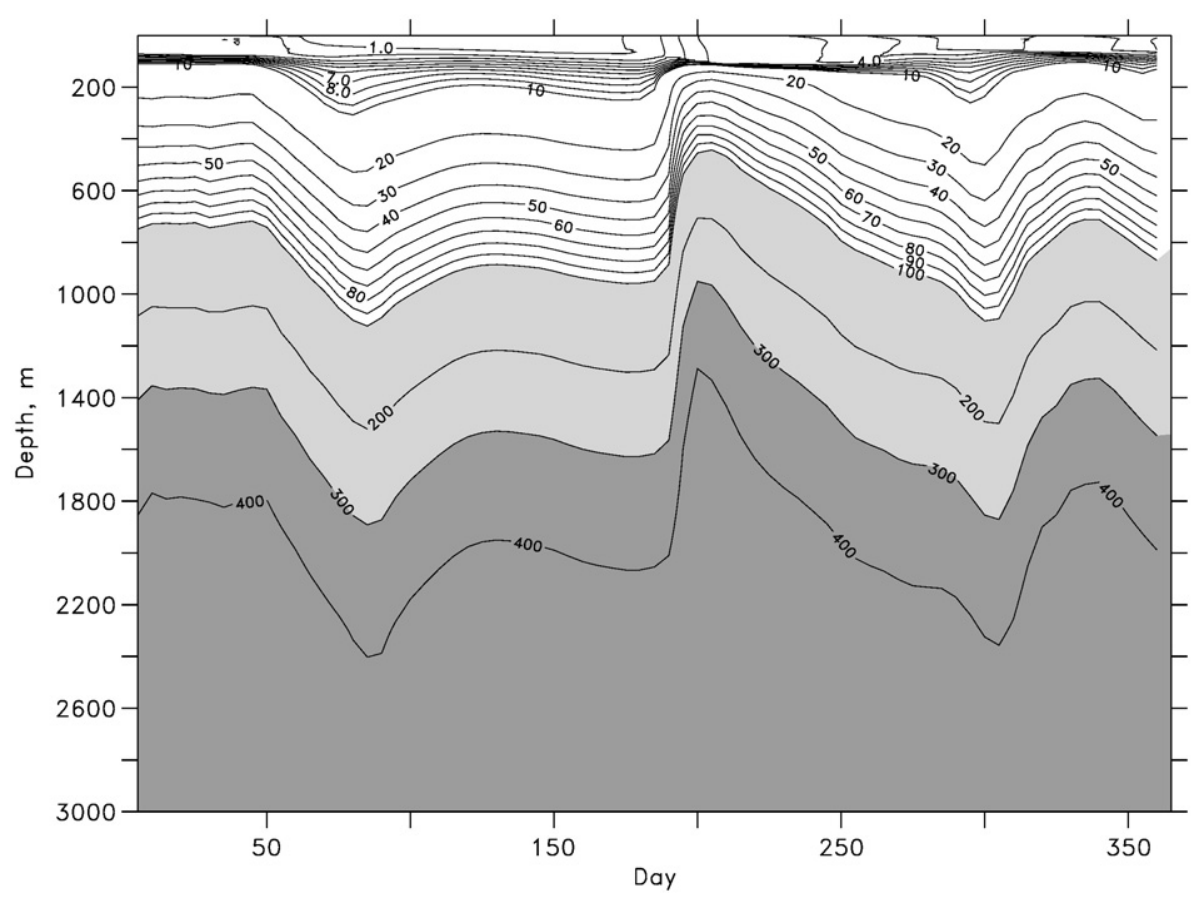

Fig. 6. Seasonal cycle of biomass sinking velocity (m/day).

the organic aggregates. To investigate the limitations of the aggregation model, we performed several experiments under changed parameterizations. These results are taken from year eighty of the respective model run. We focus on remineralization and disaggregation rate constants, and on the effect of the stickiness on aggregate formation and vertical fluxes.

\subsubsection{Remineralization and disaggregation rates}

Below the mixed layer most of the dust is derived from remineralized aggregates in form of free grains. Therefore, the remineralization rates of phytoplankton and detritus should be of crucial importance for the total dust concentrations at depth, because remineralization transfers dust particles from the rapidly sinking aggregates to the non-sinking pool of free dust particles. Current biogeochemical models employ remineralization rates between 0.004 and $0.1 \mathrm{~d}^{-1}$ (Evans and Garçon, 1997). Here we discuss the effect of 0.03 and $0.07 \mathrm{~d}^{-1}$, i.e., 0.6 and 1.4 times the rates we used in the standard run $\left(0.05 \mathrm{~d}^{-1}\right)$. Changes in the dust concentration profile are inversely related to changes in the nitrogen flux (Fig. 10). Increasing the remineralization constant from $0.05 \mathrm{~d}^{-1}$ to $0.07 \mathrm{~d}^{-1}$ results in a threefold increase of the dust concentration in the deeper layers, but only reduces the biomass flux by less than $50 \%$.

Another important process for particle cycling in the water column is the change of particle size spectra due to disaggregation. Recently, Stemmann et al. (2004a,b) and Gehlen et al. (2006) introduced several zooplankton populations including filter- and active and passive flux-feeders, who influence the particle size spectra due to aggregate mass loss and detritus production, as well as by fragmentation due to local turbulence caused by large swimming zooplankton. In the central and eastern Arabian Sea, however, suboxic waters with oxygen concentrations less than $4.5 \mu \mathrm{M}$ have been observed between 200 and $1000 \mathrm{~m}$ depth. In this depth region, oxygen becomes limiting for many higher organisms, and except for vertical migrators, mesozooplankton populations are confined to the well-oxygenated
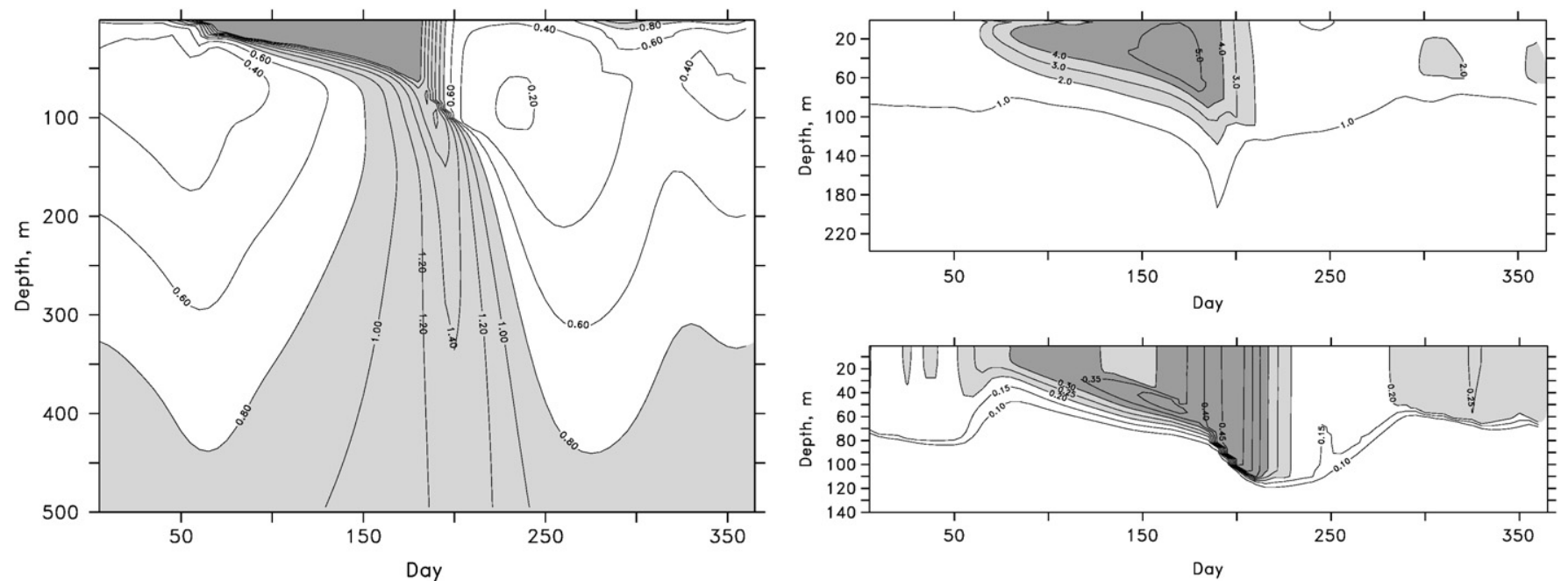

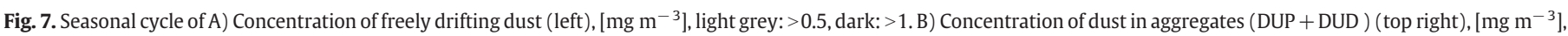
light grey $>3$, dark: $>7$ ). C) Concentration of dust in zooplankton (bottom right), light grey $>0.2$, dark: $>0.3$. 


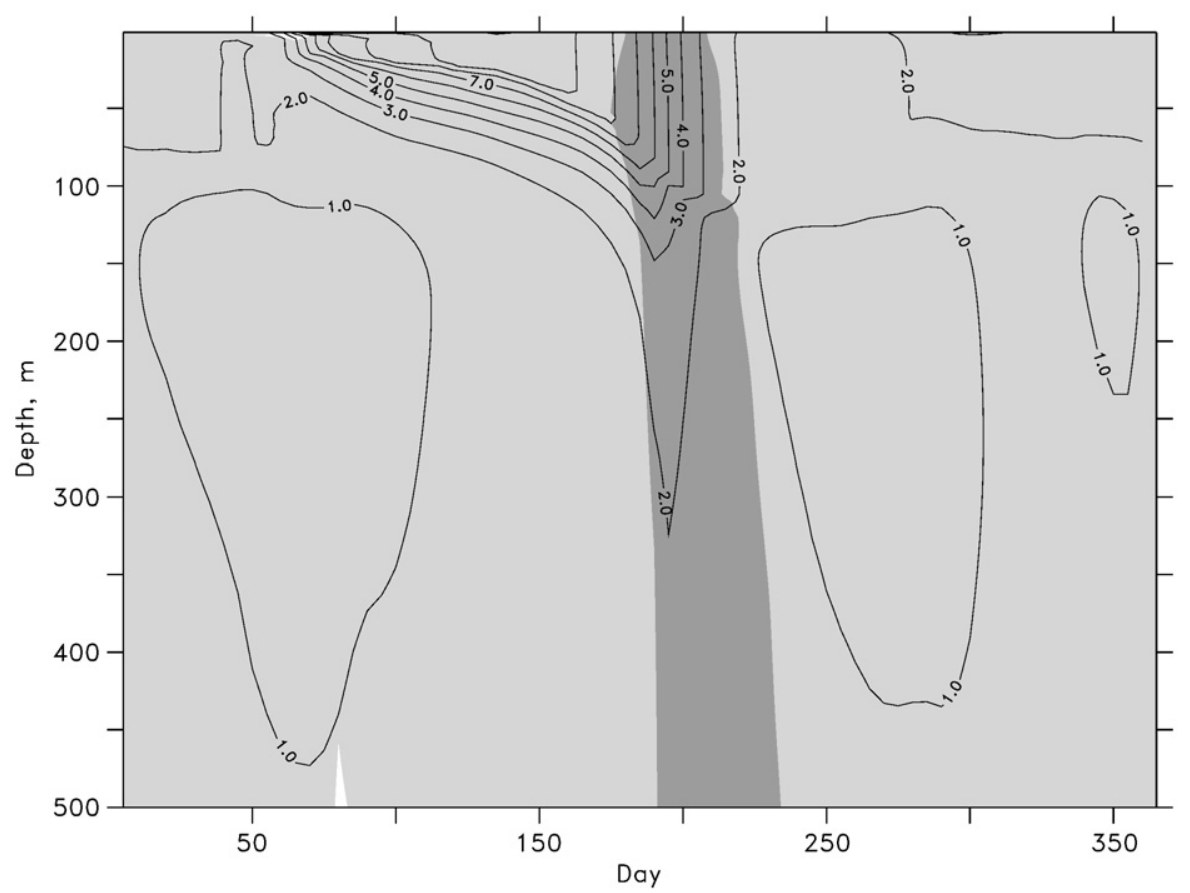

Fig. 8. Seasonal cycle of dust concentration and flux. Contours: total dust concentration, $\left[\mathrm{mg} \mathrm{m}^{-3}\right]$. Shade: total dust flux, [mg $\left.\mathrm{m}^{-2} \mathrm{~d}^{-1}\right]$, light grey: $>5$, dark: $>20$.

surface layers (Wishner et al., 1998). We therefore applied a formulation for particle breakup below the seasonal boundary layer, that takes into account the actual particle size distribution, rather than introducing additional zooplankton populations (see Appendix B). The sensitivity of the dust concentration profile and the average annual nitrogen flux to the disaggregation rate (Eq. (B14)) is shown in Fig. 11. Again, changes in the dust concentration profile are inversely related to changes in the annual nitrogen flux profile, i.e., an increase of $1 \mathrm{mg} \mathrm{N} \mathrm{m}^{-2} \mathrm{~d}^{-1}$ is responsible for a decrease of approximately $0.5 \mathrm{mg}$ dust $\mathrm{m}^{-3}$, and vice versa. Particle defragmentation affects the particle dynamics in two ways. First, the number of aggregates and as a consequence the encounter rate between biogenic aggregates and

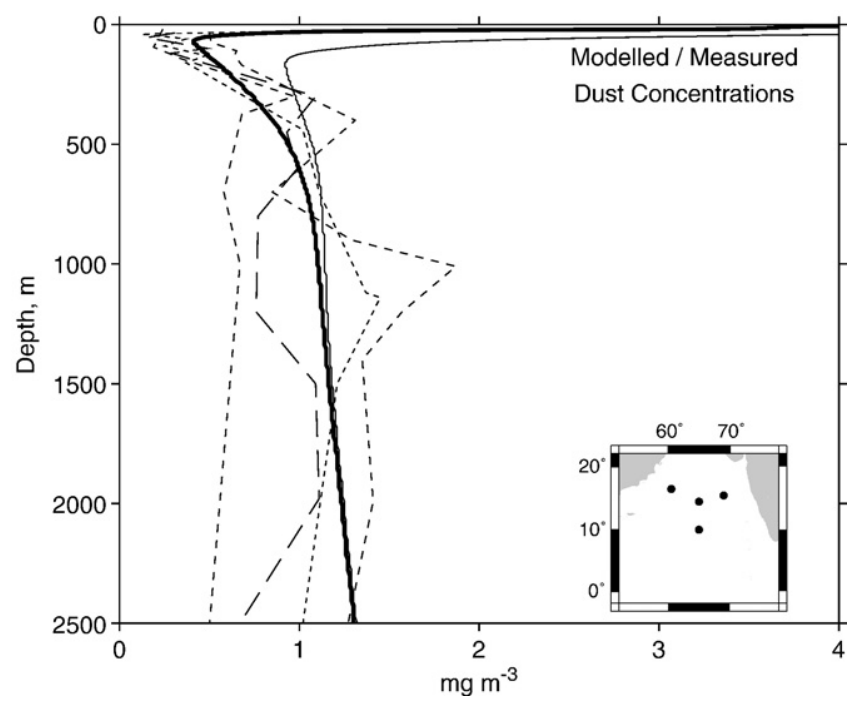

Fig. 9. Modelled (continuous lines, thin line: total dust, bold: free dust) and observed dust concentrations in the Arabian Sea. The measurements were taken at the western, eastern southern and central locations (Balzer and Schüßler, unpublished data). The modelled profile is related to the central Arabian Sea. free dust particles is increased, and second, the sinking velocity of the aggregates is reduced. Consequently, the aggregates remain longer in the water column and more dust particles are released from the sinking aggregates when biomass is decomposed. Apparently, the latter effect dominates and a new equilibrium between aggregation and release of dust particle determines the amount of free dust in the water column.

\subsubsection{Stickiness, coagulation models and integration range}

Rectilinear collision models assume that particles move in straight lines until a collision takes place, while curvilinear models take into account hydrodynamic interactions and short-range forces between approaching particles. According to Li and Logan (1997a, b), the rectilinear model could overestimate the aggregation by a factor of ten or even more. Serra and Logan (1999) observed from a paddle-mixing experiment that the collision rates between small organic aggregates $(<5 \mu \mathrm{m})$ and artificial microspheres of similar size converge to those predicted by rectilinear and curvilinear models. Collision frequencies between larger aggregates $(\sim 100 \mu \mathrm{m})$ and small microspheres were found to be 2 orders of magnitudes smaller than predicted by a rectilinear model, but 5 orders of magnitude higher than predicted using a curvilinear model. Similar inconsistencies between model prediction and physical experiments were found by Li and Logan (1997a, b) simulating the effect of differential sedimentation in a water tank. In addition, the numerical studies of Li and Zhang (2003) using sectional modelling techniques clearly showed that coagulation rates predicted by the rectilinear model are 10 times faster than those calculated by a curvilinear model. It took the rectilinear model about $800 \mathrm{~s}$ to grow the aggregates from a size of $1 \mu \mathrm{m}$ to a peak size of around $60 \mu \mathrm{m}$, while the curvilinear model required $8000 \mathrm{~s}$ to achieve a similar degree of coagulation. Li et al. (2004) argued that different collision mechanisms dominate in different size ranges which results in different particle size distributions. Brownian motion is believed to be the dominant mechanism between 0.1 and $2 \mu \mathrm{m}$. Fluid shear is considered to dominate the 2 to $60 \mu \mathrm{m}$ size range while for particles larger than $60 \mu \mathrm{m}$, differential settling becomes important. In addition, the numerical model simulated different steady state slopes 

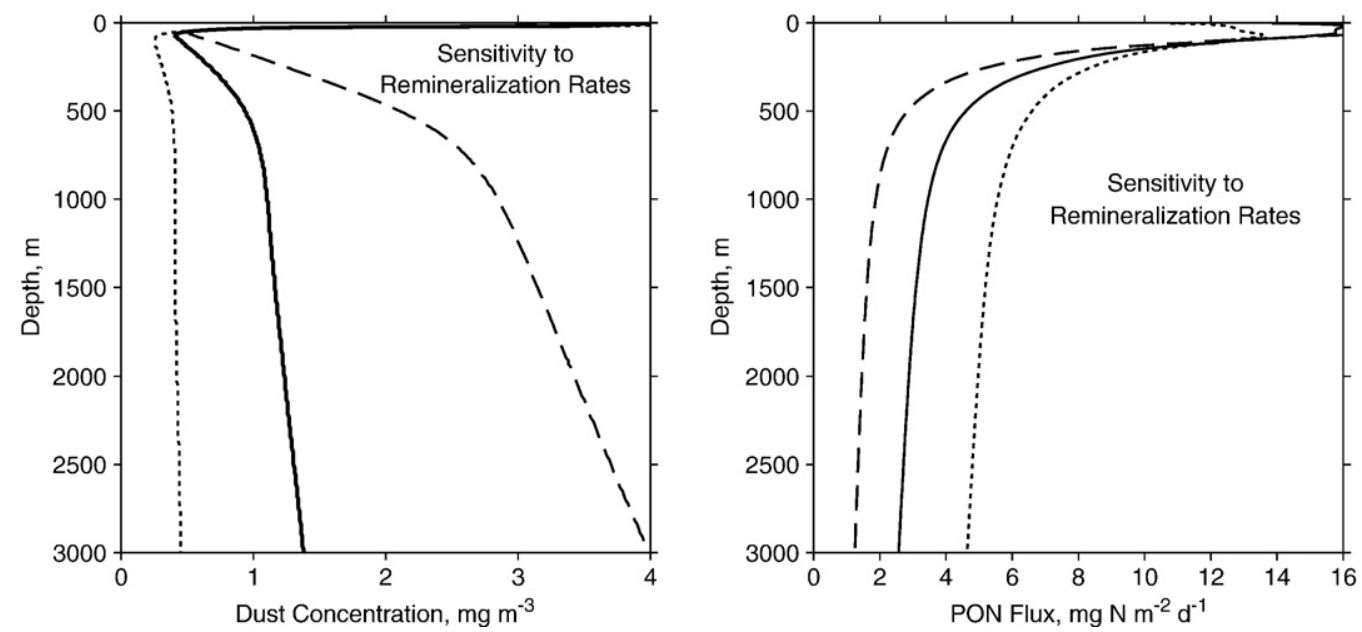

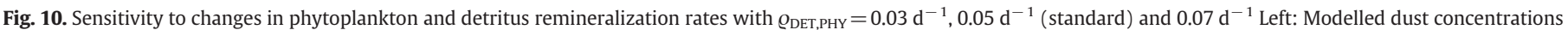
for day 100. Higher dust concentrations are related to increased remineralization. Right: Modelled annual PON flux. Higher fluxes are related to decreased remineralization.

of the particle size distribution for each of the three size ranges. Their numerical simulations were performed in a mixed water column with consistent particle fluxes into and out of the water column.

In the marine environment, however, the time and length scales may differ from those used in the physical and numerical experiments. In the turbulence regime of the upper ocean seasonal boundary layer, time and length scales can vary considerably. Typical length scales for three-dimensional turbulence range between the Kolmogorov microscale of order millimetres and the depth of the turbulent layer of order metres to hundreds of metres during winter convection. Time scales range from seconds in small scale turbulence to days and months for the diurnal and seasonal turbulent boundary layer. In the deeper ocean differential settling appears to be the only important collision mechanism, but the degradation of material and the impact of higher organisms on the sinking aggregates may become as important for the particle dynamics. Keeping this in mind, the coagulation and fragmentation processes in the ocean appear to be as badly constrained as the influences of porosity and TEP (transparent exopolymer particles) on sinking and particle stickiness (Engel and Schartau, 1999). To investigate the model's sensitivity to such effects we varied some of the model's parameter values like stickiness and the integration ranges of the mathematical formulations for aggregation and sinking, and we compared the particle capture efficiencies of the two coagulation models.

Reducing the stickiness parameter for phytoplankton/detritus aggregation (stick) by a factor of five results in a rather small decrease in the annual average of the nitrogen flux and a small increase of the dust concentration profile (Fig. 12). We conclude from these results, that changing from a rectilinear phytoplankton/detritus aggregation model to a curvilinear one may not alter the annually averaged biomass flux and the concentration of free dust significantly. Only the seasonal cycle of the dust and biomass fluxes in the deep ocean may become affected by the choice of this stickiness parameter. The model predicts a decrease of the maximum dust flux from 43 to $20 \mathrm{mg}$ dust $\mathrm{m}^{-2} \mathrm{~d}^{-1}$ and a reduction of $30 \mathrm{mg} \mathrm{C} \mathrm{m}^{-2} \mathrm{~d}^{-1}$ during the SWmonsoon period (Fig. 13).

On the other hand, reducing the aggregate-dust aggregation

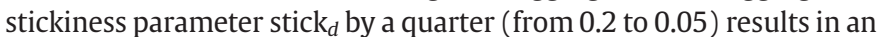
increase of the dust concentration profile by approximately a factor of four (Fig. 12). In this experiment we kept the phytoplankton/detritus stickiness (stick) to its standard value of 1 . The relationship between the different mechanisms controlling a steady state of free dust
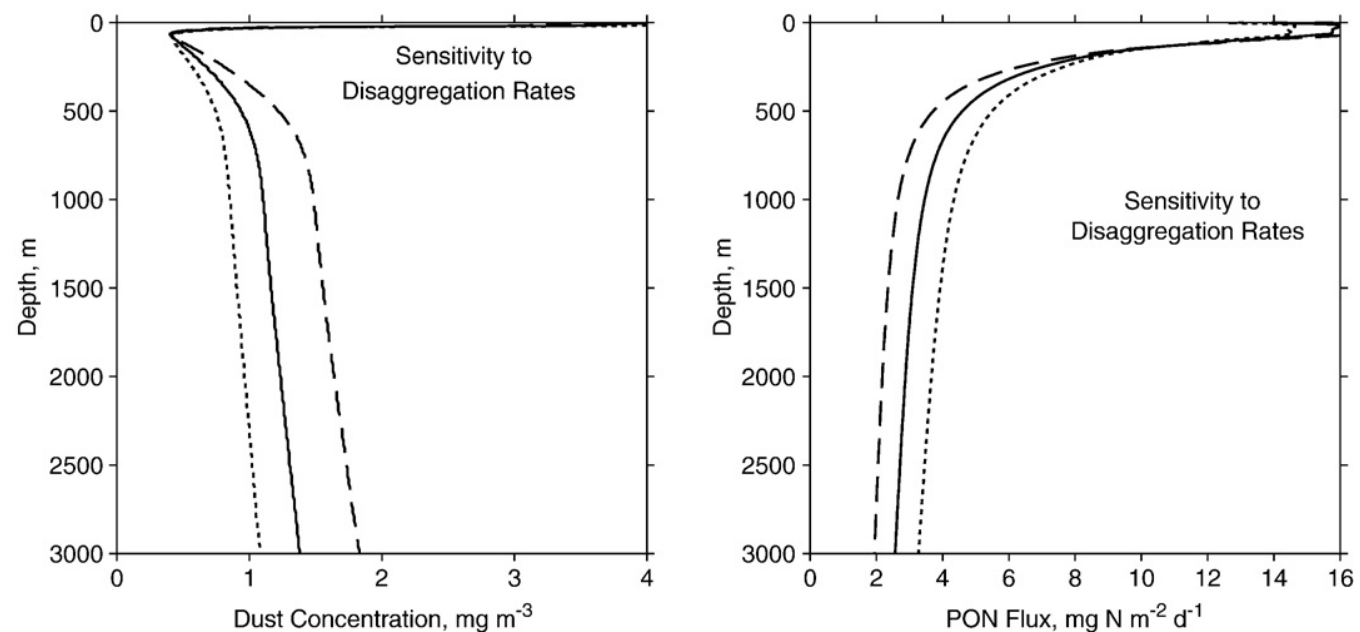

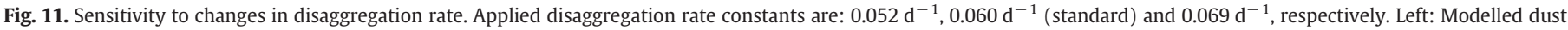

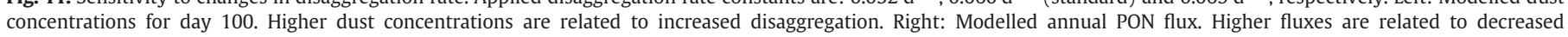
disaggregation. 

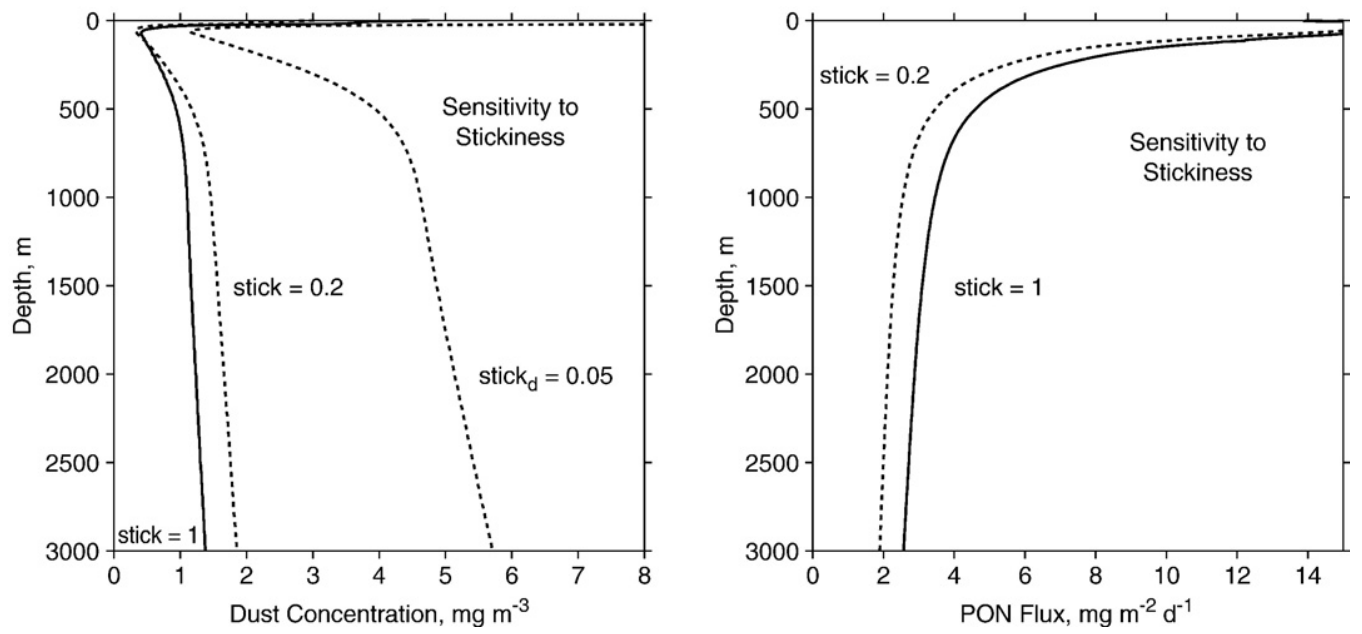

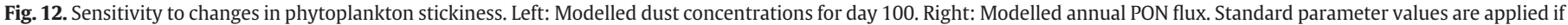
not indicated otherwise.

concentration profiles in the experiments presented in Fig. 13 can be studied with help of Eq. (1) by setting $\frac{\partial \mathrm{DUF}}{\partial t}=0$ :

$\operatorname{DUF}(z)=\frac{4 \mathrm{Q}_{\mathrm{PHY}} \mathrm{DUP}(z)+4 \mathrm{Q}_{\mathrm{DET}} \mathrm{DUD}(z)}{\pi \mathrm{NOS}(z) \operatorname{stick}_{d} f[\varepsilon(z), l, L]} ;$

where the functional relationship $\operatorname{stick}_{d} f(\varepsilon, l, L)$ refers to aggregatedust aggregation due to differential settling.

In this equation, the concentration profile of free dust particles represents a sensitive equilibrium between the release of dust grains from the aggregates due to the degradation of sinking organic materials and the product between the number of aggregates and $\operatorname{stick}_{d} f(\varepsilon, l, L)$ which depends on the particle size distribution $\varepsilon$ and the integration range $l \leq \Theta \leq L$. Consequently, changing $l$ and/or $L$ will force the solution to a different equilibrium. Similarly, variations in NOS and/or $\varepsilon$ can alter the dust profile. Since the free dust concentration closely follows the changes of stick ${ }_{d}$ in Eq. (12) (Fig. 12), we conclude that the choice of the coagulation model $f(\varepsilon(z), l, L)$ can become important for differential settling aggregation. In order to study the response to the coagulation mechanism, we compared the particle capture efficiency (PCE) as

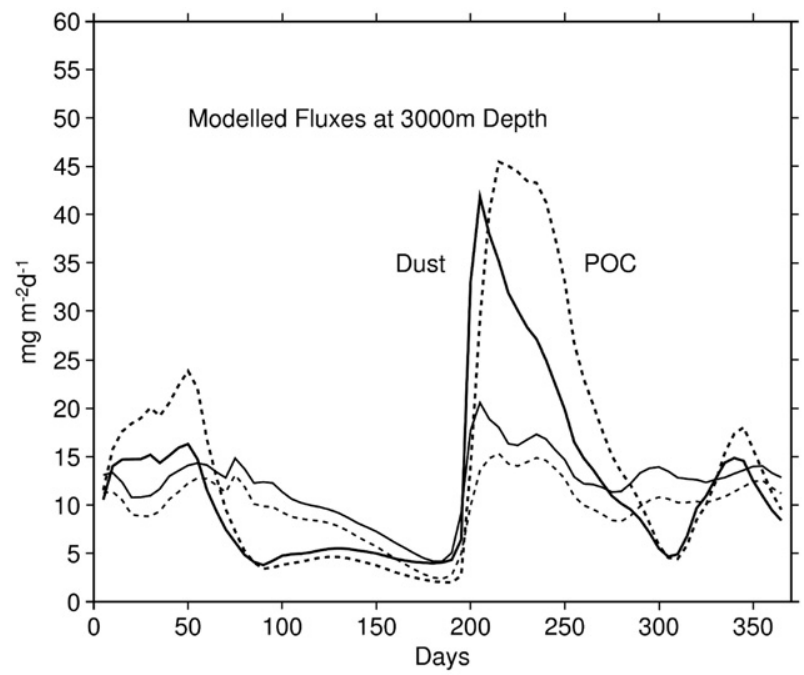

Fig. 13. Sensitivity to changes in phytoplankton stickiness. Modelled seasonal cycle of PON flux (dashed) and dust flux (continuous) at $3000 \mathrm{~m}$ depth. The bold lines (continuous and dashed) refer to stick $=1$ (otherwise stick $=0.2$ ). function of particle size distribution for several coagulation models (Fig. 14): a) curvilinear (numerical solution)

$\mathrm{PCE}=\operatorname{stick}_{d} \frac{1}{\mathrm{NOS}} \int_{m}^{\mathrm{M}} e_{\mathrm{ds}}(\Theta) \beta_{\text {sett }}(\Theta) P(\Theta) d \Theta$.

b) rectilinear:

$\mathrm{PCE}=\operatorname{stick}_{d} \frac{1}{\mathrm{NOS}} \int_{m}^{M} \beta_{\text {sett }}(\Theta) P(\Theta) d \Theta$.

c) modified rectilinear (used in this study)

$\mathrm{PCE}=\operatorname{stick}_{d} \frac{1}{\mathrm{NOS}} \int_{l}^{L} \beta_{\text {sett }}(\Theta) P(\Theta) d \Theta+\beta_{\text {sett }}(L) \int_{L}^{\infty} P(\Theta) d \Theta$

with NOS $=A \frac{m^{1-\varepsilon}}{\varepsilon-1}$ (see Appendix B). ( stick $_{d}=0.2$ in case c, otherwise stick $\left._{d}=1\right)$.

The curvilinear approach takes into account hydrodynamic interactions between the sinking aggregates and the suspended dust particles and can be approximated by a correction function for differential settling $e_{\mathrm{ds}}(\Theta)$ applied to the rectilinear model (Han and Lawler, 1992). The coefficients we used to calculate $e_{\mathrm{ds}}(\Theta)$ can be found in Li and Zhang (2003). As mentioned by Li and Logan (1997a), coagulation calculated by the rectilinear model can be several orders of magnitudes higher than that of the curvilinear approach. Surprisingly, the model we used in this study that produces the best fit to the observations, is a modified rectilinear model (Fig. 14), but the shape of the functional relationship is similar to that of the curvilinear model, except for particle size distributions in which the larger aggregates dominate the average sinking velocity $(\varepsilon<3.2)$. Since the curvilinear approach is considered to be more realistic, the number of aggregates calculated by our phytoplankton/detritus dis-/aggregation model may be underestimated and has to be compensated by a higher particle capture efficiency as approximated by the modified rectilinear version. An underestimation of the larger particles may be evident from a comparison with the US-JGOFS Camera observations by Walsh, Gardner, Richardson in the Arabian Sea (http://usjgofs.whoi.edu/jg/ serv/jgofs/arabian). Our model predicts for the size range greater than $0.5 \mathrm{~mm}$ an aggregate concentration of order $1 / \mathrm{dm}^{3}$ in the surface layers and $0.1 / \mathrm{dm}^{3}$ below, while the data shows $10 / \mathrm{dm}^{3}$ and $1 / \mathrm{dm}^{3}$, respectively.

ADAM employs an upper limit on aggregate size (parameter $M$ ) in the computation of sinking speeds and aggregation (see above). Beyond a certain size ( $1 \mathrm{~cm}$ for the standard integration) the velocity 


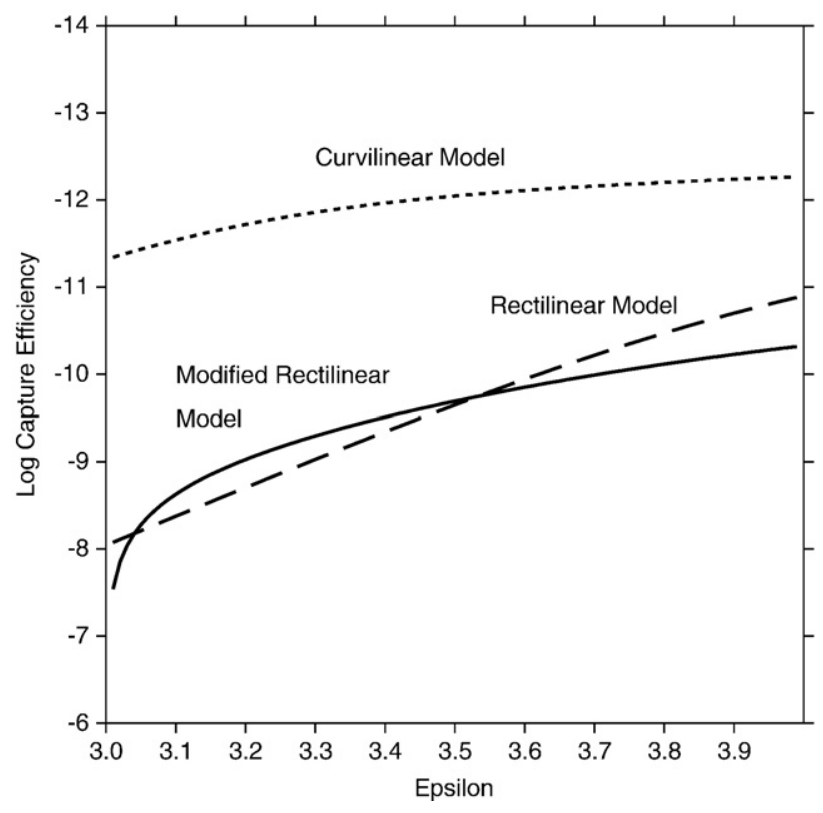

Fig. 14. Capture efficiency functions of several model approaches.

and the coagulation kernels $\beta_{\text {shear }}$ and $\beta_{\text {sett }}$ remain constant to avoid unrealistic high sinking and aggregation rates. In our sensitivity experiment, we reduced the maximum possible sinking speed from $500 \mathrm{~m}$ /day to $250 \mathrm{~m}$ /day by changing the model parameter $M$ from $1 \mathrm{~cm}$ to $0.5 \mathrm{~cm}$. Smaller or higher maximum sinking velocities may be unrealistic (Berelson, 2002). The model responds with higher dust concentrations and a reduced vertical nitrogen flux to the change on the integration range (Fig. 15). The deviations from the standard run are larger than reducing the stickiness parameter, but the results still remain within the observed quantities.

\section{Summary and discussion}

In the seasonal boundary layer (bound by the sea surface and the annual maximum of the mixed layer depth), particle cycling is controlled by the larger aggregates that sink out of the photic zone, leaving behind a steadily increasing pool of smaller aggregates with low sinking rates. Shear aggregation of particles compensates for this permanent increase of the smaller aggregates in the mixed layer, particularly during the SW and NE monsoon periods, when wind driven currents dominate the mixed layer dynamics. The interaction of the two processes controls the magnitude of the average sinking rate in this depth range. Turbulent mixing can become important after the onset of the SW-monsoon when the mixed layer deepens and aggregate parcels of different size distributions are entrained into the turbulent layers.

The employed dis-/aggregation model assumes that particulate organic nitrogen (carbon) represents the total mass of an aggregate. In fact, organic matter only contributes to approximately $10-20 \%$ to the total mass flux in the deep ocean (Jickells et al., 1996; Honjo et al., 1999) which contains besides opal and lithogenic material about $60 \%$ calcium carbonate. Since the decay of these ballast materials is less than that of organic matter (e.g., Honjo et al., 1999; Buesseler et al., 2007), size, mass and the related sinking of the aggregates eventually will be controlled by inorganic material. Consequently, the remineralization rate may have much less influence on the vertical fluxes than calculated by our model. Armstrong et al. (2002) argued that fluxes of minerals such as silicate, carbonate biominerals and dust determine the deep-water fluxes of organic carbon, but including ballast materials will require increased understanding of the processes involved.

Furthermore, the aggregation model relies on the assumption that the particle size distribution can be expressed by a single power law expression. This assumption may be valid if the size distribution stays in a constant steady state ( $\mathrm{Li}$ et al., 2004), which may not be true in natural waters, where the particle size distribution may be frequently transformed from one steady state to another by changes in the environmental variables like production rate (increase of small particles), aggregation/disaggregation, particle degradation and mixing. The time scales involved as predicted by out model are a) 2 days for cell doubling due to plankton growth, and b) 4 days for aggregate reduction caused by aggregation, degradation and separation breakup averaged over the upper $20 \mathrm{~m}$ of the mixed layer during the summer monsoon period. On the other hand, the total number of particles only increases by $5 \%$ within 50 days during that period, which suggests that vertical mixing is important as well. The time scale for mixing can be approximated by $Z^{2}=2 K_{z} t$ (Denman and Gargett, 1983), where $Z$ presents the rms vertical particle displacement and $K_{z}$ the vertical eddy mixing coefficient. Setting $Z=\mathrm{Ln}$, where $\mathrm{Ln}$ is depth of the turbulent mixed layer, the time scale for vertical movement of an aggregate around an eddy of scale Ln calculates to $11 \mathrm{~h}$ ( $25 \mathrm{~h}$ ) on day
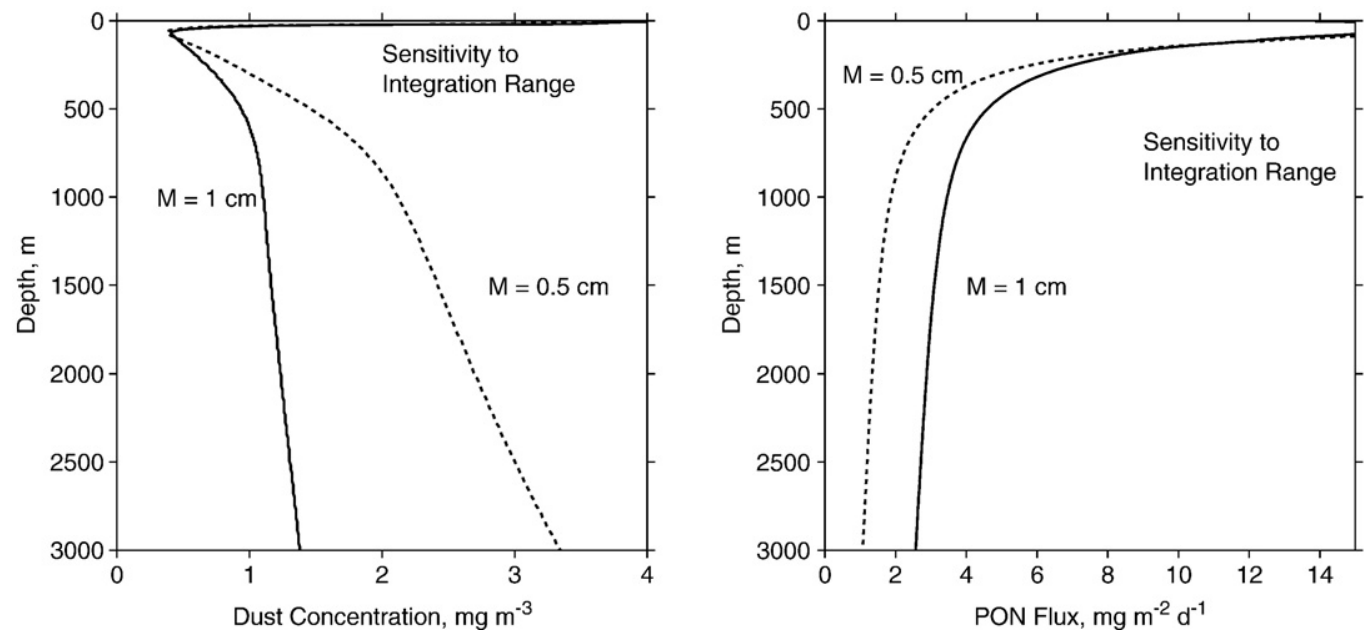

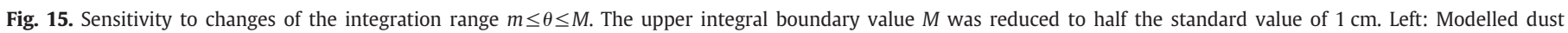
concentrations for day 100. Right: Modelled annual PON flux. 
170 (day 220) for $\mathrm{Ln}=40 \mathrm{~m}(100 \mathrm{~m})$ and $\mathrm{K}_{z}=200 \mathrm{~cm}^{2} / \mathrm{s}\left(550 \mathrm{~cm}^{2} / \mathrm{s}\right)$ (Fig. 2). Consequently, in the mixed layer, the smaller aggregates produced by the plankton bloom will be mixed downward within less than a day. To find out to what extend turbulent mixing may alter nonsteady state conditions of particle size distribution may require the use of a sectional model like the one of Riebesell and Wolf-Gladrow (1992), or an individual based approach (Barkmann and Woods 1996), which is beyond the scope of this paper. Despite these uncertainties and a rather simple parameterization of the disaggregation process, the model simulates the observations reasonably well.

Below 200 m, (i.e., in the intermediate and deep layers), fragmentation of aggregates can become an important mechanism for particle cycling. If disaggregation is neglected in the model, the larger, rapidly sinking aggregates increasingly control the particle size spectrum, thereby shifting the size distribution exponent $\varepsilon$ towards smaller values and consequently enhancing the sinking rates. Including the process of disaggregation results in more but smaller aggregates, and consequently in a reduction of the average sinking rate. Typical simulated average sinking velocities for the aggregates range between 1 and $10 \mathrm{~m} \mathrm{~d}^{-1}$ in the seasonal boundary layer and between 100 and $300 \mathrm{~m} \mathrm{~d}^{-1}$ in the deeper ocean, depending on the season. The model predicts a decrease of the annual carbon flux between $100 \mathrm{~m}$ and $3000 \mathrm{~m}$ of $80 \%$, which is close to the $86 \%$ reported by Lee et al. (1998). The majority of the biomass is kept in the small particle fraction which accounts for a standing stock smaller than $1 \mathrm{mg} \mathrm{Nm}^{-3}$ in the deeper layers (Fig. 4), while the flux of particulate organic nitrogen is carried by the larger particles.

Particle breakup increases the number of aggregates which results in higher encounter rates between the organic aggregates and the free dust grains and leads to an increased scavenging of the mineral particles. Since disaggregation reduces the average sinking velocity, the aggregates remain longer in the water column, and consequently the decay of the aggregates and the accompanying release of dust grains from the organic aggregates is enhanced. Attached dust concentration values range between 3 and $10 \mathrm{mg} \mathrm{m}^{-3}$ in the seasonal boundary layer and between 0.5 and $1 \mathrm{mg} \mathrm{m}^{-3}$ in the upper main thermocline (Fig. 8).

Observed profiles of $\mathrm{Al}$ in the SPM are characterized by low subsurface concentrations (100-200 m), and a monotonic increase through the upper main thermocline until more or less constant concentrations are reached in the intermediate and deep waters. Similar vertical patterns of particulate Al were observed by Sherrell and Boyle (1992) in the Sargasso Sea and by Sherrell et al. (1998) in the northeast Pacific. The model results compare well with these observations. (Fig. 9). The vertical distribution of the observed dust (Al) profiles as well as the concentration values around $1 \mathrm{mg} \mathrm{m}^{-3}$ in the deep ocean are reproduced by the model. Dust particle release by degradation of the sinking organic aggregates and recapture by differential settling are the main mechanisms controlling these dust profiles.

\subsection{Conclusions}

To conclude, the present phytoplankton/detritus dis-/aggregation model reacts to parameter value variations like remineralization, disaggregation and integration ranges, but it is insensitive to phytoplankton/detritus stickiness. The aggregate-dust aggregation due to differential settling, on the other hand, reacts to changes in the model parameters (see Eq. (12)), which suggests that the choice of the coagulation model may become important, and aggregate-dust stickiness and dust particle release by the decay of organic material control the free dust concentration profile. Since the model results are not sensitive to the stickiness parameter value, we did not include any mixed layer TEP dynamics (Prieto et al., 2002; Engel, 2004). Aggregate-dust stickiness in the deep ocean appears to be more important, at least in our model, but according to our knowledge there is not suitable information regarding these processes.

The model presents a mechanism that can explain how the nonsinking dust particles are being rapidly removed from the near-surface layers, and why the vertical fluxes of organic carbon and mineral particles are correlated. Introducing dust $(\mathrm{Al})$ concentration profiles in threedimensional biogeochemical circulation models as an additional observable variable puts some more constraints on the choice of the parameter values used in the phytoplankton/detritus aggregation model, since dust concentration and fluxes are strongly related to the other processes which control particle sinking and carbon fluxes. The successful reproduction by our modelling approach of three observational variables (vertical carbon (nitrogen) fluxes, deep-sea seasonal cycle of organic carbon (nitrogen) and dust fluxes, and profiles of particulate Al (dust)) also may aid during further studies of poorly constrained oceanic processes such as mineral-organic interaction, particle sinking, dis-/ aggregation and remineralization in the water column.

\section{Acknowledgments}

We wish to thank Iris Kriest for her continuous and kind collaboration and the sharing of ideas and model code regarding aggregation processes. Thanks to Simon Josey (NOC, Southampton) for supplying the forcing data sets.

We gratefully acknowledge discussions with Dr. U. Schüßler during an earlier version of this manuscript, and the efforts of A. Deeken and T. Wilkop in sampling and analyzing of the in-situ data.

This work is part of SOPRAN and the past German JGOFS programme in the Arabian Sea. It was supported by the Bundesministerium für Bildung und Forschung, BMBF, (German Federal Ministry of Education and Research) at Berlin under contract numbers 03F0462D and 03F0321C. The final version benefited from comments and suggestions of two anonymous reviewers.

\section{Appendix A. The NPZD-model}

The temporal evolution of nutrients is represented by the following equations:

$$
\begin{aligned}
& \frac{\partial \mathrm{NO}_{3}}{\partial t}=-\lambda_{\mathrm{NO}_{3}} \mathrm{PHY}+\mathrm{Q}_{\mathrm{NN}} \mathrm{NH}_{4}+\mathrm{AD}, \\
& \frac{\partial \mathrm{NH}_{4}}{\partial t}=-\lambda_{\mathrm{NH}_{4}} \mathrm{PHY}-\mathrm{Q}_{\mathrm{NN}} \mathrm{NH}_{4}+\varrho_{\mathrm{PHY}} \mathrm{PHY}+\varrho_{\mathrm{DET}} \mathrm{DET}+\mathrm{AD},
\end{aligned}
$$

where $\lambda_{\mathrm{NO} 3}$ and $\lambda_{\mathrm{NH} 4}$ denote the light- and nutrient-limited (Geider et al., 1997) nitrogen uptake rates of phytoplankton. AD represents the vertical advection and diffusion term, $\varrho_{\mathrm{PHY}}$ and $\varrho_{\mathrm{DET}}$ represent the remineralization rates of phytoplankton and detritus, and $\varrho_{\mathrm{NN}}$ is the $\mathrm{NH}_{4}$ to $\mathrm{NO}_{3}$ regeneration rate. $\mathrm{NO}_{3}$ is restored to observed values in the water column by a lateral restoring term that accounts for the vertically divergent flow of the up- and downwelling motion caused by long Rossby waves (Kawamiya and Oschlies, 2001). The annual cycle of the vertical motion is derived from the displacement of isopycnals in the Levitus Atlas.

Aggregate (bio) mass (PHY + DET) is computed prognostically by:

$$
\frac{\partial \mathrm{PHY}}{\partial t}=\left(\lambda_{\mathrm{NO}_{3}}+\lambda_{\mathrm{NH}_{4}}-\mathrm{Q}_{\mathrm{PHY}}-\mu_{\mathrm{PHY}}\right) \mathrm{PHY}-\gamma \mathrm{ZOO}+\mathrm{AD}+S_{\mathrm{PHY}},(\mathrm{A} 3)
$$

$$
\begin{aligned}
\frac{\partial \mathrm{DET}}{\partial t}= & +\mu_{\mathrm{PHY}} \mathrm{PHY}+(1-\sigma) \gamma \mathrm{ZOO}+\mu_{\mathrm{ZOO}} \mathrm{ZOO}+\phi \mathrm{ZOO}^{2} \\
& -\mathrm{Q}_{\mathrm{DET}} \mathrm{DET}+\mathrm{AD}+S_{\mathrm{DET}},
\end{aligned}
$$

with the phytoplankton and zooplankton mortalities $\mu_{\mathrm{PHY}}$ and $\mu_{\mathrm{ZOO}}$. In addition to advection and diffusion, these equations contain $S_{\mathrm{PHY}}$ and 
$S_{\mathrm{DET}}$, the rates of change due to aggregate sinking, which are given by the divergence of the respective variable's vertical flux. As explained below, this flux is computed by integrating size-dependent particle mass and size-dependent sinking velocity over the entire range of particle sizes. Therefore, $S_{\mathrm{PHY}}$ and $S_{\mathrm{DET}}$ adjust to any changes of the particle size distribution.

The zooplankton grazing rate is limited by available phytoplankton according to $\gamma=1-\exp [0.1 \max (0, \mathrm{PHY}-1)]$, thus leaving $1 \mathrm{mg} \mathrm{N} \mathrm{m}^{-3}$ of phytoplankton unaffected. $\sigma$ and $\phi$ denote the assimilation efficiency of zooplankton and its quadratic loss rate to higher trophic levels. The zooplankton equation then reads:

$\frac{\partial \mathrm{ZOO}}{\partial t}=+\sigma \gamma \mathrm{ZOO}-\mu_{\mathrm{ZOO}} \mathrm{ZOO}-\phi \mathrm{ZOO}^{2}+\mathrm{AD}$.

To account for the adaptation of phytoplankton to varying nutrient supply and light conditions during the course of a bloom, nutrientand light-limitations of phytoplankton growth $\left(\lambda_{\mathrm{NO} 3}, \lambda_{\mathrm{NH} 4}\right)$ are computed using a variable chlorophyll to carbon ratio:

$$
\frac{\partial \mathrm{CHL}}{\partial t}=\left(\lambda_{\mathrm{NO}_{3}}+\lambda_{\mathrm{NH}_{4}}\right) \rho_{\mathrm{CHL}} \mathrm{CAR}-\left(\mu_{\mathrm{PHY}}+\mathrm{Q}_{\mathrm{PHY}}+\gamma \frac{\mathrm{ZOO}}{\mathrm{PHY}}\right) \mathrm{CHL}+\mathrm{AD},
$$

CAR $=$ Redfield Ratio $\cdot$ PHY

$\rho_{\mathrm{CHL}}=\theta_{m}\left(\frac{P^{c}}{\alpha I \theta}\right)$

$\rho_{\mathrm{CHL}}$ denotes the carbon-specific chlorophyll growth rate as in Geider et al. (1997). $\theta$ and $\theta_{m}$ are the chl:carbon and maximum chl:carbon ratios, respectively. $\alpha$ represents the chl-specific initial slope of the photosynthetic-light curve, and $P^{c}$ is the carbon-specific photosynthetic rate $(I=$ irradiance). Water- and chlorophyll-specific light attenuation is computed over 25 spectral bands using the formulae of Horch et al. (1983) and Morel (1988).

\section{Appendix B. The aggregation model}

Since the KE99 model is well documented (KE99; Kriest, 1999; Kriest and Evans, 2000; Kriest, 2002; Maier-Reimer et al., 2005; Gehlen et al., 2006), we restrict the discussion of the model to the appropriate equations that define particle size distribution and sinking.

Variations of total aggregate numbers are proportional to the change rates of aggregate mass, the reduction rate due to aggregation, $\xi$, and the increase due to disaggregation, $\psi$ :

$$
\begin{aligned}
\frac{\partial \mathrm{NOS}}{\partial t}= & \frac{\mathrm{NOS}}{\mathrm{PHY}+\mathrm{DET}}\left[\left(\beta\left(\lambda_{\mathrm{NO}_{3}}+\lambda_{\mathrm{NH}_{4}}\right)-\mathrm{Q}_{\mathrm{PHY}}\right) \mathrm{PHY}-\mathrm{Q}_{\mathrm{DET}} \mathrm{DET}\right. \\
& \left.+\left(\mu_{\mathrm{ZOO}}+\phi \mathrm{ZOO}-\sigma \gamma\right) \mathrm{ZOO}\right]-\xi+\psi+\mathrm{AD}+S_{\mathrm{NOS}}
\end{aligned}
$$

where the proportionality constant $1 /\left(\mathrm{NOS} \mathrm{Cm}^{\zeta}\right)$ is time dependent. $\beta$ denotes the probability of cell separation after cell doubling.

Based on the work of KE99 we modelled the aggregate dynamics in the context of a continuous particle size spectrum according to McCave (1984) and Bader (1970):

$P(\Theta)=A \Theta^{-\varepsilon}$,

$P(\Theta)=A \Theta^{-\varepsilon}$ where $\Theta$ is the aggregate diameter and $\varepsilon$ determines the shape of the size distribution. The total number concentration of aggregates (NOS) can be written as

NOS $=\int_{m}^{\infty} P(\Theta) d \Theta=A \frac{m^{1-\varepsilon}}{\varepsilon-1}$.
With the average number of cells per aggregate,

$N=(\mathrm{PHY}+\mathrm{DET}) /\left(\operatorname{NOS} \mathrm{Cm}^{\zeta}\right)$,

it follows that the aggregate size distribution evolves in time and space according to

$\varepsilon=\frac{(1+\zeta) N-1}{N-1}$

$\varepsilon$ defines the slope of the particle size distribution, it is an important diagnostic variable that controls aggregation, disaggregation and sinking. To avoid division by zero and numerical errors due to divisions by extremely small numbers, we kept the values of $\varepsilon$ between 3.01 and 3.99 by increasing or decreasing the number of aggregates where appropriate. The corresponding biomass sinking speeds (Eq. (B9)) range between $460 \mathrm{~m} / \mathrm{d}(\varepsilon=3.01)$ and $0.5 \mathrm{~m} / \mathrm{d}$ $(\varepsilon=3.99)$. This correction only applies in the photic zone during a short time interval in spring when chlorophyll concentrations are low (Figs. 3 and 5), and for extremely high sinking velocities in the deep ocean.

The sinking speed of an aggregate $w(\theta)$ is parameterized by a simple power law expression (Smayda, 1970; Alldredge and Gotschalk, 1988)

$w_{\Theta}=B \Theta^{\eta}$.

and the vertical flux of the total number concentration is given by the integral over the product of $w(\Theta)$ and $P(\Theta)$ :

$\Phi_{\mathrm{agg}}=w \mathrm{NOS}=A B \int_{m}^{\infty} \Theta^{\zeta-\varepsilon} d \Theta$.

The integration range is split into two subranges, $m \leq \Theta \leq M$ and $M<\Theta \leq \infty$, to avoid aggregation and sinking becoming unrealistically high. For the latter subrange, the aggregation kernels are kept constant by substituting $M$ for $\Theta$. A similar expression for the vertical biomass flux can be derived from the integral of the product $w(\theta) \mathrm{P}(\Theta)$ $\mathrm{C}_{\mathrm{m}}(\Theta)$, where

$C_{m}(\Theta)=C \Theta^{\zeta}$

$C_{m}(\Theta)$ is the biomass of an aggregate

$\Phi_{\text {bio }}=A B C \int_{m}^{\infty} \Theta^{\eta+\zeta-\varepsilon} d \Theta$

Finally, the average sinking speeds for biomass and number of aggregates are calculated from

$w_{\text {bio }}=\frac{B \int_{m}^{\infty} \Theta^{\eta+\zeta-\varepsilon} d \Theta}{\int_{m}^{\infty} \Theta^{\zeta-\varepsilon} d \Theta} ; w_{\text {agg }}=\frac{B \int_{m}^{\infty} \Theta^{\eta-\varepsilon} d \Theta}{\int_{m}^{\infty} \Theta^{-\varepsilon} d \Theta} ;$

and

$S_{\mathrm{PHY}}=\frac{\partial\left(w_{\mathrm{bio}} \mathrm{PHY}\right)}{\partial z} ; S_{\mathrm{DET}}=\frac{\partial\left(w_{\mathrm{bio}} \mathrm{DET}\right)}{\partial z} ;$

$S_{\mathrm{NOS}}=\frac{\partial\left(w_{\mathrm{agg}} N O S\right)}{\partial z} ;$

$\xi$ is computed as in Kriest (1999) and KE99:

$\xi=0.5$ stick $\int_{m}^{\infty} \int_{m}^{\infty}\left(\beta_{\text {shear }}(\theta, \Theta)+\beta_{\text {sett }}(\theta, \Theta) P(\theta) P(\Theta)\right) d \theta d \Theta$

with

$\beta_{\text {shear }}=0.163 \operatorname{shear}(\theta+\Theta)^{3} ; \beta_{\text {sett }}=0.125 \pi B \Theta^{2}\left(\Theta^{\eta}-\theta^{\eta}\right)$;

shear is a parameter that refers to horizontal velocity shear. 


\section{The disaggregation term, $\psi$}

So far, the model is similar to that of KE99 with the exception that here both phytoplankton cells and detritus particles contribute to the aggregates. Aggregate decay is modelled as gradual and proportional loss of mass and per aggregate particle number during remineralization. Aggregate breakage is considered to be an additional important process affecting particle size distribution and particle dynamics in the marine environment. Disaggregation of marine aggregates occurs in turbulent boundary layers where shear forces and pressure differences act across the particle to break it apart (Ruiz and Izquierdo, 1997). In the mostly laminar regime of the thermocline and in the ocean's interior, drag and frictional forces in combination with biological processes that weaken the particle structure, may be responsible for the disaggregation of the aggregates. In addition, zooplankton fecal pellets which are the major components of the sinking organic material, may disaggregate into smaller particles when the membrane embracing them is remineralized. The fragmentation of larger particles into smaller ones along with the new number of particles and their size distribution is difficult if not impossible to predict (Jackson and Burd, 1998). Consequently, present disaggregation models applied to turbulent boundary layers rely on stochastic formulations of the relevant processes (e.g., Hill, 1996; Ruiz and Izquierdo, 1997), use simpler parameterizations extracted from measured break up rates (Jackson, 1995) or estimate the impact of mesozooplankton on fragmentation and biomass loss in the deep ocean (Stemmann et al., 2004a,b). All these models have in common that their formulations are based on discrete particle size distributions. However, incorporating aggregate break up into a continuous particle size model requires an appropriate formulation for the increase in the total number concentration of aggregates (NOS), which in turn changes the particle size distribution (Eq. (B4)), and consequently the sinking speed of the aggregates.

Since the parameters and coefficients describing the forces acting on sinking aggregates and the inherent binding forces are poorly known, we introduce a simple parameterization for the breakup of aggregates which may be sufficient to describe the disaggregation process below the mixed layer. In our model, the disaggregation rate depends on the number of aggregates and on the sinking velocity, i.e., it is inversely related to $\varepsilon$ :

$\psi(z)=\operatorname{NOS}(z)\left[\frac{1}{\varepsilon(z)-\eta-\zeta}-1\right] \kappa_{0} e^{-\lambda z}$

where $\kappa_{0}$ is a rate constant which has to be determined from comparison with observations. The hyperbolic relationship spans four orders of magnitudes, from 99 for particle size distributions with the slope $\varepsilon=3.01$, to 0.01 for $\varepsilon=3.99$. We introduced the depth dependent relationship since aggregates which have arrived at a certain depth are considered to be less vulnerable to fragmentation processes than their counterparts above.

The disaggregation term $\psi$ forces the model to produce more, but smaller and slower aggregates and reduces biogenic fluxes (slower sinking of otherwise unchanged mass).

\section{Appendix C. Model parameters}

There are numerous parameters for defining the rates of nitrogen and dust transfers associated with the different processes. The values given in Table 1 were applied to the model runs discussed in this publication.

\section{References}

Alldredge, A.L., Gotschalk, C., 1988. The in situ settling behaviour of marine snow. Limnology and Oceanography 33, 339-351.

Alldredge, A.L., Jackson, G.A., 1995. Aggregation in marine systems. Deep-Sea Research II $42,1-7$.
Armstrong, R.A., Lee, C., Hedges, J.I., Honjo, S., Wakeham, S.G., 2002. A new mechanistic model for organic carbon fluxes in the ocean based on the quantitative association of POC with ballast minerals. Deep-Sea Research II 49, 219-236.

Bader, H., 1970. The hyperbolic distribution of particle sizes. Journal of Geophysical Research 75, 2822-2830.

Barber, R.T., Marra, J., Bidigare, R.C., Codispoti, L.A., Halpern, D., Johnson, Z., Latasa, M. Goericke, R., Smith, S.L., 2001. Primary productivity and its regulation in the Arabian Sea during 1995. Deep-Sea Research II 48, 1127-1172.

Barkmann, W., Woods, J.D., 1996. On using a Lagrangian model to calibrate primary production determined from in vitro incubation measurements. Journal of Plankton Research 18, 767-788.

Berelson, W.M., 2002. Particle settling rates increase with depth in the ocean. Deep-Sea Research II 49, 237-251.

Buesseler, K.O., Lamborg, C.H., Boyd, P.W., Lam, P.J., Trull, T.W., Bidigare, R.R., Bishop, J.K., Casciotti, K.L., Dehairs, F., Elskens, M., Honda, M., Karl, D.M., Siegel, A., Silver, M.W. Steinberg, D.K., Valdes, J., Van Mooy, B., Wilson, S., 2007. Revisiting carbon flux through the ocean's twilight zone. Science 316, 567-570.

Burd, A.B., Jackson, G.A., 1997. Predicting particle coagulation and sedimentation rates for a pulsed input. Journal of Geophysical Research 102, 10545-10561.

Burd, A.B., Moran, S.B., Jackson, G.A., 2000. A coupled adsorption-aggregation model of the POC ${ }^{234}$ Th ratio of marine particles. Deep-Sea Research I 47, 103-120.

Clegg, S.L., Whitfield, M., 1990. A generalized model for the scavenging of trace metals in the open ocean - I. Particle cycling. Deep-Sea Research 17, 809-832.

Cochran, J.K., Buessler, K.O., Bacon, M.P., Livingston, H.D., 1993. Thorium isotopes as indicators of particle dynamics in the upper ocean: results from the JGOFS North Atlantic Bloom Experiment. Deep-Sea Research I 40, 1569-1595.

Dadou, I., Lamy, F., Rabouille, C., Ruiz-Pino, D., Andersen, V., Bianchi, M., Garçon, V. 2001. An integrated biological pump model from the euphotic zone to the sediment: a 1-D application in the Northeast tropical Atlantic. Deep-Sea Research Il $48,2345-2381$.

Denman, K.L., Gargett, A.E., 1983. Time and space scales of vertical mixing and advection of phytoplankton in the upper ocean. Limnology and Oceanography 28 , $801-815$

Denman, K.L., Gargett, A.E., 1995. Biological-physical interactions in the upper ocean the role of vertical and small-scale processes. Annual Reviews of Fluid Mechanics 27, 225-255.

Deuser, W.G., Ross, E.H., Anderson, R.F., 1981. Seasonality in the supply of sediment to the deep Sargasso Sea and implications for the rapid transfer of matter to the deep ocean. Deep-Sea Research 28A, 495-505.

Deuser, W.G., Brewer, P.G., Jickells, T.D., Commeau, R.F., 1983. Biological control of the removal of abiogenic particles from the surface ocean. Science 219, 388-391.

Doney, S.C., Glover, D.M., Najjar, R.G., 1996. A new coupled, one-dimensional biological-physical model of the upper ocean: applications to the JGOFS Bermuda Atlantic Time Series (BATS) site. Deep-Sea Research II 43, 591-624.

Engel, A., 2004. Distribution of transparent exopolymer particles (TEP) in the northeast Atlantic Ocean and their potential significance for aggregation processes. Deep-Sea Research I 51, 83-92.

Engel, A., Schartau, M., 1999. Influence of transparent exopolymer particles (TEP) on sinking velocity of Nitzschia closterium aggregates. Marine Ecology Progress Series $182,69-76$.

Evans, G.T., Garçon, V.C., 1997. One-dimensional models of water column biogeochemistry. JGOFS Report 23, p. 85.

Fisher, N.S., Hook, S.E., 2002. Toxicology tests with aquatic animals need to consider the trophic transfer of metals. Toxicology 181 (182), 531-536.

Gaspar, P., Gregoris, Y., Lefevre, J.-M., 1990. A simple eddy kinetic energy model for simulations of the oceanic vertical mixing: tests at station Papa and long-term upper ocean study site. Journal of Geophysical Research 95 (C9), 16179-16193.

Gehlen, M., Bopp, L., Emprin, N., Aumont, O., Heinze, C., Ragueneau, O., 2006. Reconciling surface ocean productivity, export fluxes and sediment composition in a global biogeochemical ocean model. Biogeosciences 3, 521-537.

Geider, R.J., McIntyre, H.L., Kana, T.M., 1997. Dynamic model of phytoplankton growth and acclimation: responses of the balanced growth rate and the chlorophyll $a$ : carbon ration to light, nutrient-limitation and temperature. Marine Ecology Progress Series 148, 187-200.

Gelbard, F., Tambour, Y., Seinfeld, J.H., 1980. Sectional representations for simulating aerosol dynamics. Journal of Colloid and Interface Science 76 (2), 541-556.

Haake, B., Ittekkot, V., Rixen, T., Ramaswamy, V., Nair, R.R., Curry, W.B., 1993. Seasonality and interannual variability of particle fluxes to the deep Arabian Sea. Deep-Sea Research I 40, 1323-1344.

Han, M.Y., Lawler, D.F., 1992. The (relative) insignificance of G in flocculation. Journal of the American Water Works Association 84, 79-91.

Haupt, O.J., Wolf, U., von Bodungen, B., 1999. Modelling the pelagic nitrogen cycle and vertical particle flux in the Norwegian sea. Journal of Marine Systems 19, 173-199.

Hill, P.S., 1996. Sectional and discrete representations of floc breakage in agitated suspensions. Deep-Sea Research I 43, 679-702.

Honjo, S., Dymond, J., Prell, W., Ittekkot, V., 1999. Monsoon-controlled export fluxes to the interior of the Arabian Sea. Deep-Sea Research II 46, 1859-1902.

Horch, A., Barkmann, W., Woods, J.D., 1983. Die Erwärmung des Ozeans hervorgerufen durch solare Strahlungsenergie. Berichte Institut für Meereskunde Kiel 120, 75.

Jackson, G.A., 1990. A model for the formation of marine algal flocs by physical coagulation processes. Deep-Sea Research 37, 1197-1211.

Jackson, G.A., 1995. Comparing observed changes in particle size spectra with those predicted using coagulation theory. Deep-Sea Research II 42, 159-184.

Jackson, G.A., Burd, A.B., 1998. Aggregation in the marine environment. Environmental Science \& Technology 32, 2805-2814. 
Jickells, T.D., Newton, P.P., King, P., Lampitt, R.S., Boutle, C., 1996. A comparison of sediment trap records of particle fluxes from 19 to $48 \mathrm{~N}$ in the northeast Atlantic and their relation to surface water productivity. Deep-Sea Research I 43, 971-986.

Kawamiya, M., Oschlies, A., 2001. Formation of a basin-scale surface chlorophyll pattern by Rossby waves. Geophysical Research Letters 28, 4139-4142.

Kinkade, C.S., Marra, J., Dickey, T.D., Weller, R., 2001. An annual cycle of phytoplankton biomass in the Arabian Sea, 1994-1995, as determined by moored optical sensors. Deep-Sea Research II 48, 1285-1301.

Kriest, I., 1999. The influence of phytoplankton aggregation on sedimentation model study. Ph. D. thesis, University of Kiel, Germany, $136 \mathrm{pp}$.

Kriest, I., 2002. Different parameterizations of marine snow in a 1D-model and their influence on representation of marine snow, nitrogen budget and sedimentation. Deep-Sea Research I 49, 2133-2162.

Kriest, I., Evans, G.T., 1999. Representing phytoplankton aggregates in biogeochemical models. Deep-Sea Research I 46, 1841-1859.

Kriest, I., Evans, G.T., 2000. A vertically resolved model for phytoplankton aggregation. Proceedings of the Indian Academy of Sciences (Earth and Planetary Sciences) 109 453-469.

Kumar, S.P., Ramaiah, N., Gauns, M., Sarma, V.V.S.S., Muraleedharan, P.M., Raghukumar, S., Kumar, M.D., Madhupratap, M., 2001. Physical Forcing of biological productivity in the Northern Arabian Sea during the Northeast Monsoon. Deep-Sea Research II $48,1115-1126$.

Lee, C., Murray, D.W., Barber, R.T., Buesseler, K.O., Dymond, J., Hedges, J.J., Honjo, S., Manganini, S.J., Marra, J., Moser, C., Peterson, M.L., Prell, W.L., Wakeham, S.G., 1998 Particle organic fluxes: compilation of results from the 1995 US JGOFS Arabian Sea Process Study. Deep-Sea Research II 45, 2489-2501.

Levitus, S., Boyer, T.P., 1994. World Ocean Atlas 1994 Volume 4. Temperature. : NESDIS, 4. NOAA Atlas, p. 117.

Li, X.Y. Logan, B.E., 1997a. Collision frequencies of fractal aggregates with small particles by differential sedimentation. Environmental Science \& Technology 31, $1229-1236$

Li, X.Y., Logan, B.E., 1997b. Collision frequencies of fractal aggregates with small particles in a turbulently sheared fluid. Environmental Science \& Technology 31 1237-1242.

Li, X.Y., Zhang, J.J., 2003. Numerical simulation and experimental verification of particle coagulation dynamics for a pulsed input. Journal of Colloid and Interface Science $262,149-161$.

Li, X.Y., Zhang, J.J., Lee, J.H.W., 2004. Modelling particle size distribution dynamics in marine waters. Water Research 38, 1305-1313.

Maier-Reimer, E., Kriest, I., Segschneider, J., Wetzel, P., 2005. The Hamburg Ocean Carbon Cycle Model HAMOCC 5.1. Reports on Earth System Science Technical Description Release 1.1. Max Planck Institute for Meteorology, Hamburg, Germany, p. 49.

McCave, I.N., 1984. Size spectra and aggregation of suspended particles in the deep ocean. Deep-Sea Research 31, 125-138.

Morel, A., 1988. Optical modelling of the upper ocean in relation to its biogenous matter content (case I waters). Journal of Geophysical Research 93 (C9) 10749-10768.

Murnane, R.J., Sarmiento, J.L., Bacon, M.P., 1990. Thorium isotopes, particle cycling models, and inverse calculations of model rate constants. Journal of Geophysical Research 95 (C9), 16195-19206.

Murnane, R.J., Cochran, J.K., Sarmiento, J.L., 1994. Estimates of particle- and thoriumcycling rates for the northwest North Atlantic. Journal of Geophysical Research 99 (C2), 3373-3392.

Murnane, R.J., Cochran, J.K., Buesseler, K.O., Bacon, M.P., 1996. Least-squares estimates of thorium, particle, and nutrient cycling rate constants from the JGOFS North Atlantic Bloom Experiment. Deep-Sea Research I 43, 239-258.

Passow, U.P. Shipe, R.F. Murray, A., Pak, D.K., Brzezinski, M.A. Alldredge, A.L., 2001. The origin of transparent exopolymer particles (TEP) and their role in the sedimentation of particulate matter. Continental Shelf Research 21 (4), 327-346.
Pätsch, J., Kühn, W, Radach, G, Santana Casiano, J.M., Gonzalez Davila, M., Neuer, S, Freudenthal, T., Llinas, O., 2002. Interannual variability of carbon fluxes at the North Atlantic Station ESTOC. Deep-Sea Research II 49, 253-288.

Pondaven, P., Fravalo, C., Ruiz-Pino, D., Tréguer, P., Quéguiner, B., Jeandel, C., 1998. Modelling the silica pump in the permanently open ocean zone of the Southern Ocean. Journal of Marine Systems 17, 587-619.

Press, W.H., Flannery, B.P., Teukolsky, S.A., Vetterling, W.T., 1986. Numerical recipes. Cambridge University Press, Cambridge. 818 pp.

Prieto, L., Ruiz, J., Echevarria, F., Garcia, C.M., Bartual, A., Galvez, J.A., Corzo, A., Macias, D., 2002. Scales and processes in the aggregation of diatom blooms: high time resoution and wide size range records in a mesocosm study. Deep-Sea Research I 49, $1233-1253$.

Ramaswamy, V., Nair, R.R., Manganini, S., Haake, B., Ittekkot, V., 1991. Lithogenic fluxes to the deep Arabian Sea measured by sediment traps. Deep-Sea Research 38, 169-184.

Riebesell, U., Wolf-Gladrow, D., 1992. The relationship between physical aggregation of phytoplankton and particle flux: a numerical model. Deep-Sea Research 39, 335-357.

Ruiz, J., Izquierdo, A., 1997. A simple model for the break up of marine aggregates by turbulent shear. Oceanologica Acta 20, 597-605.

Schüßler, U., Balzer, W., Deeken, A., 2005. Dissolved Al distribution, particulate Al fluxes and coupling to atmospheric Al and dust deposition in the Arabian Sea. Deep-Sea Research II 52, 1862-1878.

Serra, T., Logan, B.L., 1999. Collision frequencies of fractal bacterial aggregates with small particles in a sheared fluid. Environmental Science \& Technology 33, 2247-2251.

Sherrell, R.M., Boyle, E.A., 1992. The trace metal composition of suspended particles in the oceanic water column near Bermuda. Earth and Planetary Science Letters 111, 155-174.

Sherrell, R.M., Field, M.P., Gao, Y., 1998. Temporal variability of suspended mass and composition in the Northeast Pacific water column: relationships to sinking flux and lateral advection. Deep-Sea Research II 45, 733-761.

Skogen, M.D., 1999. A biophysic model applied to the Benguela upwelling system. South African Journal of Marine Science 21, 235-249.

Slagstad, D., Wassmann, P., 2001. Modelling the 3-D carbon flux across the Iberian margin during the upwelling season 1998. Progress in Oceanography 51, 467-497.

Smayda, T.J., 1970. The suspension and sinking of phytoplankton in the sea. Oceanography and Marine Biology: An Annual Review 8, 353-414.

Stemmann, L., Jackson, G.A., Ianson, D., 2004a. A vertical model of particle size distributions and fluxes in the midwater column that includes biological and physical processes-Part I: model formulation. Deep-Sea Research I 51, 865-884.

Stemmann, L., Jackson, G.A., Gorsky, G. 2004b. A vertical model of particle size distributions and fluxes in the midwater column that includes biological and physical processes-Part II: application to a three year survey in the NW Mediterranean Sea. Deep-Sea Research I, 51, 885-908. 51, 865-884.

Tett, P., 1998. Parameterising a microplankton model. Report Department of Biological Sciences, Napier University, Edinburgh, p. 106. ISBN 0902703609.

Twining, B.S., Fisher, N.S., 2004. Trophic transfer of trace metals from protozoa to mesozooplankton. Limnology and Oceanography 49, 28-39.

Weller, R.A., Baumgartner, M.F., Josey, S.A., Fischer, A.S., Kindle, J., 1998. Atmospheric forcing in the Arabian Sea during 1994-1995: observations and comparisons with climatology and models. Deep-Sea Research 45, 1961-1999.

Wishner, K.F., Gowing, M.M., Gelfman, C., 1998. Mesozooplankton biomass in the upper $1000 \mathrm{~m}$ in the Arabian Sea: overall seasonal and geographic patterns, and relationship to oxygen gradients. Deep-Sea Research II 45, 2405-2432. 